Estudios Constitucionales, Año 8, No 2, 2010, pp. 247 - 292.

ISSN 0718-0195

Centro de Estudios Constitucionales de Chile Universidad de Talca

"Las garantías judiciales como vías de tutela de los derechos fundamentales en estados de emergencia (in) constitucional"

Federico Justiniano Robledo

\title{
LAS GARANTÍAS JUDICIALES COMO VIIAS DE TUTELA DE LOS DERECHOS FUNDAMENTALES EN ESTADOS DE EMERGENCIA (IN) CONSTITUCIONAL
}

\author{
JUDICIAL WARRANTS AS A WAY TO PROTECT FUNDAMENTAL RIGHTS \\ in EMERgency States (IN) Constitutional
}

\author{
Federico Justiniano Robledo* \\ Profesor de Derecho Público Provincial y Derecho Municipal \\ de la Universidad Nacional de Córdoba, Argentina. \\ avilapaz@satlink.com
}

RESUMEN: El presente trabajo constituye un ensayo reflexivo sobre uno de los grandes ejes que nos plantea el Derecho Constitucional Comparado y el Derecho Internacional de los Derechos Humanos en materia de Estados de Emergencia para el siglo XXI: la función de las Garantías Judiciales como vías de tutela efectiva de los derechos fundamentales.

El desarrollo conceptual lo realizamos a partir de una visión integrativista y desde una mirada constitucional dinámica y evolutiva. Se escudriña su dimensión normativa, poniendo el acento particular en el horizonte constitucional comparado, el Sistema Interamericano de Derechos Humanos y MERCOSUR.

Finalmente, se proponen reflexiones y lineas de análisis que parten de una relectura de la materia en clave con el fortalecimiento de la tutela judicial efectiva de los derechos humanos en tiempos de excepción.

ABSTRACT: This paper constitute a reflexive essay about one of the fundamental issues that Comparative Constitutional Law and International Law of Human Rights, present in Emergency States for 21st century: the role of judicial warrants as a way to effectively protect fundamental rights.

With an integrational and constitutional (dynamical and developer) points of view we explain the concepts ut supra mentioned. We focus the normative dimension in Comparative Constitutional Law, Interamerican Human Rights System, and MERCOSUR's Law.

\footnotetext{
* Abogado, Doctor en Derecho y Ciencias Sociales, Académico de Número y actual Secretario de la Academia del Plata -Sección Córdoba- (R.A.), Profesor de Derecho Público Provincial y Derecho Municipal de la Universidad Nacional de Córdoba -UNC-, Profesor de Derecho Constitucional y de Derecho Público Provincial y Derecho Municipal de la Universidad Católica de Salta, Premio al Mérito Federal otorgado por el Instituto de Federalismo de la Academia Nacional de Derecho y Ciencias Sociales de Córdoba, Miembro de la Comisión Directiva del Área de Estudios de América Latina -A.E.A.L.- de la Facultad de Derecho y Ciencias Sociales de la U.N.C. (R.A.), Miembro de la Asociación Argentina de Derecho Constitucional y del Instituto de Federalismo de la Academia Nacional de Derecho y Ciencias Sociales de Córdoba, Ex Secretario Relator de Fiscalía de Estado de la Provincia de Córdoba. Enviado el 22 de noviembre de 2009, aprobado el 22 de septiembre de 2010.
} 
Finally, we present some reflection and analysis, re-reading the judicial effective protection of human rights for it strengthening, in exceptional moment.

PalabRas Clave: Emergencia. Estado de emergencia. Garantías judiciales. Amparo. Hábeas corpus. Bloque de constitucionalidad. Sistema interamericano de derechos humanos. Democracia. MERCOSUR.

KEY WORDS: Emergency. Emergency State. Judicial Warrants. Writ of Habeas Corpus. Constitutional. Interamerican Human Rights System. Democracy. MERCOSUR.

"Toda sociedad en la que la garantía de los derechos no está asegurada ni la separación de poderes establecida no tiene constitución".

Art. 16 de la Declaración de los Derechos del Hombre y del Ciudadano (Francia, 26-08-1789) ${ }^{1}$

\section{Preliminares}

El mundo actual "nos muestra con crudeza que los estados de emergencia han sido (...) la regla del funcionamiento jurídico de muchos paises"2.

La persistencia de las crisis y la ausencia de imaginación han hecho que a una emergencia le siga otra y a ésta una nueva emergencia o el retorno a la anterior, convirtiéndose la normalidad y la estabilidad en utopías, ${ }^{3}$ invirtiéndose los conceptos de regla y excepción.

En alusión a ello, parte de la doctrina las ha calificado como un caballo de Troya que ha ingresado hacia el interior de la democracia, desvirtuándola muchas veces hasta convertirla en una "emergentocracia"'.

Se trata de un tema de suma actualidad y gran complejidad, que ha sido abordado con enfoques integrativistas, que se nutren de los aportes de la economía, sociología jurídica, ciencia política y derecho, entre otras disciplinas.

En lo que respecta estrictamente a la dimensión jurídica, observamos a las emergencias con gran preocupación. Su aparición multiplicada -muchas veces excesiva- y permanencia alongada en el tiempo, operan como factores de "desconstitucionalización" y "desmontaje de la Constitución". 5

\footnotetext{
${ }^{1}$ Díaz Revorio, F. Javier (2004), p. 129.

${ }^{2}$ SAlvioli, Fabián Omar (1997), p. 197.

${ }^{3}$ Rosatti, Horacio Daniel (2009): "Un círculo vicioso: impacto de las emergencias continuadas en el diseño institucional de Argentina. Emergencia y división de poderes", [fecha de consulta: 01/07/09]. Disponible en Biblioteca Virtual de la Universidad Autónoma de México: www.juridicas.unam.mx/publica/rev/revlad/ cont/1/art/art15.htm
}

${ }^{4}$ Cfr. Midón, Mario (2009).

${ }^{5}$ Sobre este tópico, ver SAGÜÉs, Néstor Pedro (2007). El citado autor, desarrollando el pensamiento de Kägy, explica que el "derecho de emergencia" refrendado por una lectura de la Constitución entrevista como la 
Se ha resaltado que entre el Estado de Derecho y la emergencia existe una lógica inversamente proporcional. La característica fundamental del Estado de Derecho es la limitación racional del poder, primando los "medios" sobre los "fines", edificándose el poder público sobre el respeto a reglas y procedimientos (Bobbio). La emergencia, en cambio, es "finalista"; pone su mirada en los objetivos más que en los medios para alcanzarlos, "siempre más cerca de Maquiavelo que de Kant". Dalla Vía grafica esta situación como "la cuadratura del círculo".

No podemos soslayar el célebre ensayo de Bruce Ackerman titulado "The Emergency Constitution", publicado en el YALE Law Journal, ${ }^{8}$ en el cual, partiendo de la experiencia de abusos repetidos en los estados de emergencia y el reverdecimiento de esta doctrina a la luz de los ataques terroristas del 11 de septiembre de 2001, plantea como un desafío de este siglo XXI la búsqueda de una nueva Constitución, que contenga una respuesta eficaz a corto plazo en los estados de excepción y la superación de estados de excepción permanentes, en aras de brindar mayor tutela a los derechos fundamentales y libertades civiles. ${ }^{9}$

En la misma tesitura, el jurista italiano Giuseppe di Vergottini, destaca como uno de los grandes problemas de la emergencia: la alteración del sistema institucional establecido y sus consecuencias directas en relación con la protección y tutela de los derechos fundamentales. ${ }^{10}$

Por nuestra parte, advertimos que la reflexión de la materia sub examine, gira en torno de dos grandes ejes: el quebrantamiento de las competencias normales de los parlamentos a favor del poder ejecutivo (Habërle) ${ }^{11}$ y la limitación o suspensión de determinadas garantías judiciales en ejercicio de los poderes de emergencia (Tyler). ${ }^{12}$

El presente trabajo pone el acento en el segundo de los ejes precitados. Se pretende indagar en torno al papel que cumplen las garantías judiciales para la

\footnotetext{
"Constitución extraordinaria o de emergencia", que desvincula al operador gubernativo de controles y responsabilidades, y que magnifica un derecho de emergencia intra o extraconstitucional constituye un indicador de desmontaje constitucional.

${ }^{6}$ Cfr. Dalla Vía, Alberto Ricardo (2009).

${ }^{7}$ Midón, Mario, ob. cit.

${ }^{8}$ ACKERMAN, Bruce (2004).

${ }^{9}$ A modo de contestación y réplica al ensayo de Ackerman, ver Tribe, Lawrence y Gudridge, Patrick O. (2004).

${ }^{10}$ Cfr. Domínguez Zorrego, Manuel (1993), pp. 265 y ss.

${ }^{11}$ Habërle, Peter (2001): El Estado Constitucional (Perú, Universidad Nacional Autónoma de México y Pontificia Universidad Católica del Perú), p. 292.

${ }^{12}$ Tyler, Amanda (2009).
} 
protección de las libertades y derechos fundamentales en tiempos de excepción. Nos preguntamos: ¿son las garantías judiciales vías idóneas para proteger los derechos fundamentales en los estados de emergencia o sólo son, tomando la imagen de Nino ${ }^{13}$, el vestido invisible de aquel rey que sólo él creía que lo protegía porque todos los demás asi lo decian?

Cabe aclarar que, sin desconocer que la emergencia es un fenómeno jurídico que impacta en todo orbe, en el presente trabajo se realiza un corte metodológico que implica una mirada más profunda a los Estados que forman parte del Sistema Interamericano de Derechos Humanos y una particular mención a los que integran el MERCOSUR.

\section{Hacia una deFinición de EMERGENCIA Y ESTAdos DE EMERGENCIA}

Definir la emergencia no es tarea sencilla.

En primer término, porque se trata de un fenómeno, cuya comprensión integral no es posible sino a través del camino de la interdisciplina. Es un concepto jurídico, pero no es sólo un concepto jurídico.

En segundo término, porque el concepto denotativo ${ }^{14}$ de "emergencia" se ha ensanchado ampliamente en los últimos tiempos, incorporándose en su extensión nuevos supuestos de hecho que ampliaron notablemente sus fronteras (por ejemplo: emergencia ambiental, emergencia hídrica, emergencia por ataques terroristas, emergencia sanitaria por epidemias nuevas -v. gr. Gripe A H1N1-, emergencia carcelaria, emergencias por crisis económico-financieras sin precedentes, emergencia judicial, etc). Más aún, creemos que la complejidad de la realidad continuará gravitando en la producción de nuevas situaciones que podrán catalogarse como "emergencia". ${ }^{15}$ Todo ello, nos indica que estamos en frente de un fenómeno evolutivo, cuya aproximación demanda de interpretación dinámica, que se ajuste a la realidad.

Hechas estas consideraciones, cabe señalar que el vocablo emergencia -del latín emergens, - entis-, ${ }^{16}$ se utiliza, en su acepción jurídica, para definir una situación

\footnotetext{
${ }^{13}$ Cfr. Nino, Carlos Santiago (1992), p. 15.

${ }^{14}$ Nino, Carlos Santiago (2000), pp. 251-252.

${ }^{15}$ Genaro Carrió, al referirse al lenguaje natural y lenguaje jurídico, enseña que los términos y conceptos jurídicos no pueden asemejarse a los conceptos de la geometría, en que unos y otros están integrados por un número determinado de elementos necesarios, que no se pueden tocar sin que la figura (jurídica o geométrica) se desmoronen. Existe una zona de penumbra, en la que se ubican los casos marginales y dudosos. Asimismo, "Il]a complejidad de las situaciones de hecho desborda las clasificaciones tradicionales". Cfr. CARrRIÓ, Genaro R. (1973), pp. 39-40.

${ }^{16}$ Real Academia Española (2010): Diccionario de la Lengua Española, Vigésima Segunda Edición.
} 
de intranquilidad pública -estado de alarma o estado de sitio-, situaciones de urgencia o excepción. ${ }^{17}$

En el pensar de Peter Habërle, la emergencia comprende todas las situaciones de peligro grave para la permanencia del Estado o de la seguridad y el orden público, que no pueden resolverse mediante las vías normales previstas por la Constitución, sino que requieren de medios excepcionales. Agrega el jurista germano, que el objetivo de cualquier disposición sobre situaciones de emergencia debe ser el restablecimiento, tan pronto sea posible de la "normalidad constitucional". La idea de la ultima ratio o de la prohibición de exceso debe guiar a todas las medidas de excepción, como el quebrantamiento (Durchbrechung) de las competencias normales de los parlamentos a favor del Ejecutivo (concentración de poderes) o de la limitación o suspensión temporales de los derechos fundamentales. Bajo estas estrictas condiciones requiere la primacía de la Constitución Escrita, suspender en parte la Constitución, "a fin de poder restablecer su vigencia ilimitada". Es en esta medida, que el Estado de Excepción forma parte plenamente de las instituciones "normales" del Estado Constitucional y no se encuentra, per se, en contradicción con él. ${ }^{18}$

Es claro que cuando el Estado atraviesa situaciones de emergencia - guerras, conmociones internas, desórdenes domésticos o crisis económicas-, que ponen en jaque la normalidad constitucional, se torna necesario y urgente disponer de medidas para conjurarlas, contenerlas y superarlas. Cabe precisar que las Constituciones contemplan la emergencia y prescriben los medios para enfrentarlos. El Poder Público aumenta circunstancial y transitoriamente la órbita de sus competencias, con desplazamientos de facultades a favor de uno de sus órganos (Poder Ejecutivo) que debe enfrentar y neutralizar las crisis con fuertes medidas y sanciones legales, posibilitando la aplicación de leyes y medidas más severas. Para ello, suele invocar el restablecimiento del orden y del Estado de Derecho, la seguridad pública, y disponer de medidas con arraigo constitucional en el propio texto escrito, como suspensión de garantías, estado de sitio, medidas de seguridad, ley marcial, entre otros. Se justifica su implementación sin arbitrariedad, sin improvisaciones, tanto en el derecho privado como público, en la medida que sea con racionalidad técnica y moral de los medios empleados, y sin exceder los límites que la Constitución le impone.

No obstante lo dicho, no debe olvidarse que la sociedad, a la cual sirve el Estado en el cumplimiento insoslayable del bien común, está integrada por

${ }^{17}$ Cabanellas, Guillermo (1953), pp. 36-38.

${ }^{18}$ Cfr. HabËrle, Peter, ob. cit., pp. 292 y ss. 
personas humanas que nacen y quieren vivir en libertad, en el marco de su dignidad que justificó y justifica su lucha permanente en la historia de la humanidad, con lo cual toda medida de excepción debe ser realmente de excepción, para no afectar ilegítimamente los derechos y garantías fundamentales de los hombres.

Debe recordarse que el constituyente de la Edad Moderna, impuso límites al ejercicio del poder de sus órganos y escribió con tinta eterna en las Constituciones sus derechos, deberes y garantías, para recordarle que el desborde causa dolor y deshumanización en sus actos políticos y son de insanable inconstitucionalidad y nulidad. Todo abordaje de la emergencia que eluda u omita esta situación resulta peligrosa.

Por otra parte, es dable recordar a Bermúdez Tapia, quien enumera las características del régimen de emergencia y excepción:

1. Concentración del poder, con permisión constitucional, en un solo detentador -normalmente el jefe del Ejecutivo-, mediante la concesión de un conjunto de competencias extraordinarias, a efectos de que la acción estatal sea tan rápida y eficaz como lo exijan las graves circunstancias de anormalidad que afronta la comunidad politica. Fruto de ello, es el acrecentamiento de las atribuciones de las Fuerzas Armadas y de la Policía.

2. Existencia o peligro inminente de una grave circunstancia de anormalidad, cuyo origen puede ser de naturaleza politico-social, o deberse a situaciones de fuerza mayor o crisis económicas. Tales los casos de guerra exterior, guerra civil, revuelta, motines, revoluciones, cataclismos, maremotos, inflaciones, deflaciones, etc.

3. Imposibilidad de resolver las situaciones de anormalidad a través del uso de los procedimientos legales ordinarios.

4. Transitoriedad del régimen de excepción. Habitualmente, su duración se encuentra prevista en la Constitución o en las leyes derivadas de ésta; o en su defecto, regirá por el tiempo necesario para conjurar la situación de anormalidad.

5. Determinación espacial del régimen de excepción. La acción del Estado se focalizará en el lugar donde se producen estas situaciones de anormalidady las medidas, por tanto, tendrán carácter nacional, regional o local.

\section{Restricción transitoria de determinados derechos constitucionales.}

7. Aplicación de medidas con criterio de razonabilidad y proporcionalidad. Tendrán como fin sostener y defender la perdurabilidad y normal funcionamiento de la organización política-jurídica.

8. Control jurisdiccional expresado en la verificación jurídica de la aplicación de los principios de razonabilidad y proporcionalidad del acto restitutivo o suspensivo de los derechos fundamentales de la persona, y en el cumplimiento del iter procedimental 
exigido por la Constitución para establecer su decretamiento; así como en el uso del control político parlamentario para que se cumplan los principios de rendición de cuentas y de responsabilidad politica ${ }^{19}$ ".

Desde el punto de vista pretoriano, ha sido conceptualizada y desarrollada a través de la jurisprudencia. Por ejemplo, en el caso de Argentina, la Corte Suprema de Justicia de la Nación ha sentado precedentes importantes para comprender el contenido, características y alcances de la emergencia. Ha señalado que ésta puede derivar de situaciones de carácter físico (terremotos, epidemias), económico-social, o político (revolución), pudiendo ser de naturaleza diversa. Asimismo, ha establecido como notas tipificantes: a) su modo de ser extraordinario; b) la gravedad y amplitud de sus efectos, y c) la necesidad imperiosa de establecer normas adecuadas para resolverla, en función de los intereses afectados, reglas que no son propias del derecho ordinario: acontecimientos extraordinarios reclaman remedios también extraordinarios ${ }^{20}$.

Por su parte, el Tribunal Constitucional de Perú ha desarrollado interesantes conceptos vinculados con los estados de emergencia y excepción:

“(...) la vida institucional no es siempre uniforme, permanentemente lineal, ni absolutamente previsora del acontecer coexistente cual dentro de una comunidad politica; por el contrario, ante los avatares de la historia, la sensatez acredita la necesidad de que el Estado esté premunido de los instrumentos necesarios para afrontar aquellas situaciones extraordinarias que impiden el cumplimiento de los fines de la sociedad estatal y que amenacen su perdurabilidad como tal.

El régimen de excepción conceptualmente hace referencia a aquellas "competencias de crisis" que la Constitución otorga al Estado con el carácter de extraordinaria, a efectos de que pueda afrontar hechos, sucesos o acontecimientos que, por su naturaleza, ponen en peligro el normal funcionamiento de los poderes públicos o amenazan la continuidad de las instituciones estatales y los principios básicos de convivencia dentro de una comunidad politica" ${ }^{21}$.

Por su parte, Antonio M. Hernández, al estudiar esta anormalidad en la historia institucional argentina arribó a preocupantes conclusiones, que nos brindan una visión de la materia teñida de realidad:

\footnotetext{
${ }^{19}$ Cfr. Bermúdez Tapia, Manuel Alexis (2007), pp. 506-507.

${ }^{20}$ Cfr. Dalla Vía, Alberto Ricardo, ob. cit.

${ }^{21}$ Expte. No 0017 - 2003 - AI/TC - Lima. (2003): Tribunal Constitucional de Perú 16 de marzo de 2004 (acción de inconstitucionalidad), [fecha de consulta: 23/03/2010]. Disponible en: http://www.tc.gob.pe/ jurisprudencia/2004/00017-2003-AI.html
} 
1. "Como respuesta a las distintas emergencias sufridas, se utilizaron diferentes institutos de emergencia, previstos, no previstos o prohibidos por la Constitución $\mathrm{Na}$ cional";

2. "El ejercicio de estos institutos produjo severas lesiones a nuestro Estado de Derecho, al orden constitucional, al sistema republicano, y a los derechos individuales";

3. "En todos los casos observados de utilización de los institutos, el Poder Ejecutivo actuó de manera exorbitante, profundizando el hiperpresidencialismo que hemos padecido";

4. "El Poder Legislativo también fue responsable de estos desaciertos institucionales al actuar así, sea en forma activa como pasiva u omisiva, pues en algunos casos acompañó las politicas del Ejecutivo, mediante la sanción de las leyes respectivas o al efectuar las delegaciones en aquél y en otros casos, al no efectuar control político alguno de las medidas, abdicando de sus funciones esenciales";

5. "En cuanto al Poder Judicial, y salvo los casos excepcionales puntualizados, no se apreció un correcto y firme ejercicio de sus facultades de control de constitucionalidad, lo que evidenció su falta de independencia y de cumplimiento de su rol como poderes del Estado republicano";

6. "Agregamos ahora que las emergencias han sido una de las causas principales de la anomia que padecemos, por lo que se debe terminar con la legislación de emergencia y la práctica abusiva de los decretos de necesidad y urgencia y la legislación delegada"22.

\section{LAS GARANTÍAS JUDICIALES}

La Corte Interamericana de Derechos Humanos nos suministra una primera aproximación a la noción de "garantía", al señalar que "... [la]s garantías sirven para proteger, asegurar o hacer valer la titularidad o el ejercicio de un derecho. Como los Estados Partes tienen la obligación de reconocer y respetar los derechos y libertades de la persona, también tienen la de proteger y asegurar su ejercicio a través de las respectivas garantías (art. 1.1), vale decir, de los medios idóneos para que los derechos y libertades sean efectivos en toda circunstancia'"3.

En este mismo sentido, Alvarado Velloso sostiene que "[s]on garantías constitucionales todos los medios e institutos de seguridad jurídica otorgados a favor de los individuos para que ellos puedan lograr el reconocimiento efectivo de un derecho

${ }^{22}$ Hernández, Antonio María (2007), p. 28.

${ }^{23}$ Corte Interamericana de Derechos Humanos (1987): "Opinión Consultiva O.C. 8/87 del 30/01/1987 - "El Hábea Corpus bajo Suspensión de Garantías (Arts. 27.2, 25.1 y 7.6 Convención Americana sobre Derechos Humanos)", párr. 25, [fecha de consulta: 23/03/2010]. Disponible en: http://www.corteidh.or.cr/ docs/opiniones/seriea_08_esp.pdf 
vulnerado en un momento dado. ${ }^{\text {"24 }}$. Por su parte, Joaquín V. González las define en los siguientes términos: "Il]as garantías son todas aquellas seguridades y promesas que ofrece la Constitución al pueblo argentino, y a todos los hombres, de que sus derechos generales y especiales han de ser sostenidos y defendidos por las autoridades y por el pueblo mismo; y se consignan ya porque son inherentes a toda sociedad de hombres libres o iguales, ya porque se ha querido separar errores o abusos del pasado"25.

En el sistema jurídico constitucional se han diseñado diversas garantías específicas: amparo, hábeas corpus y hábeas data, todas las cuales deben desenvolverse de conformidad al "debido proceso adjetivo" (art. 18 Constitución Nacional Argentina, y arts. 8 C.A.D.H.).

En primer lugar, debemos referirnos a la vía procesal del amparo, la cual ha sido receptada a nivel constitucional tanto en su modalidad "individual" como "colectiva".

El art. $431^{\text {er }}$ Párrafo de la Constitución Nacional argentina, regula el amparo individual en los siguientes términos:

"Toda persona puede interponer acción expedita y rápida de amparo, siempre que no exista otro medio judicial más idóneo, contra todo acto u omisión de autoridades públicas o de particulares, que en forma actual o inminente lesione, restrinja, altere o amenace, con arbitrariedad o ilegalidad manifiesta, derechos y garantías reconocidos por esta Constitución, un tratado o una ley. En el caso, el juez podrá declarar la inconstitucionalidad de la norma en que se funde el acto u omisión lesiva".

El art. $432^{\circ}$ párrafo, regula amparo colectivo:

"Podrán interponer esta acción contra cualquier forma de discriminación y en lo relativo a los derechos que protegen al ambiente, a la competencia, al usuario y al consumidor, así como a los derechos de incidencia colectiva en general, el afectado, el defensor del pueblo $y$ las asociaciones que propendan a esos fines, registradas conforme a la ley, la que determinará los requisitos y formas de su organización".

Cabe señalar que a la fecha la Ley No $16.986^{26}$ reglamentaria del amparo, sólo contempla su faz individual, mas no su faz colectiva.

En segundo lugar, la vía procesal del hábeas corpus, la que se encuentra receptada expresamente en el art. 43 in fine Constitución Nacional argentina:

${ }^{24}$ Alvarado Velloso, Adolfo (1998), p. 208.

${ }^{25}$ GonZÁlez, Joaquín V. (1964), p. 130.

${ }^{26}$ Ley No 16.986, “Acción de Amparo”. B.O. 20/10/1966. 
"Cuando el derecho lesionado, restringido, alterado o amenazado fuera la libertad fisica, o en caso de agravamiento ilegitimo en la forma o condiciones de detención, o en el de desaparición forzada de personas, la acción de hábeas corpus podrá ser interpuesta por el afectado o por cualquiera en su favor y el juez resolverá de inmediato, aun durante la vigencia del estado de sitio".

Esta garantía de hábeas corpus ha sido reglamentada por medio de la Ley No $23.098^{27}$.

La Corte Suprema de Justicia de la nación argentina ha extendido esta vía procesal para la tutela de derechos de incidencia colectiva en el precedente: Fallos: 328:1146, "Verbitsky, Horacio", 03/05/05.

En tercer lugar, la vía procesal del hábeas data, la que se encuentra receptada expresamente en el art. $433^{\text {er }}$ párrafo:

"Toda persona podrá interponer esta acción para tomar conocimiento de los datos a ella referidos y de su finalidad, que consten en registros o bancos de datos públicos, o los privados destinados a proveer informes, y en caso de falsedad o discriminación, para exigir la supresión, rectificación, confidencialidad o actualización de aquéllos. No podrá afectarse el secreto de las fuentes de información periodistica".

Esta garantía de hábeas data sido reglamentada por medio de la Ley No $25.326^{28}$.

Recientemente se ha extendido la vía del hábeas data a la tutela de derechos de incidencia colectiva en un caso de la Cámara Nacional Civil caratulado: "Unión de Usuarios y Consumidores c. Citibank NA", LL, 2006-D, 225.

\section{LAS GARANTÍAS JUDICIALES EN EL MARCO DE SITUACIONES DE EMERGENCIA O EXCEPCIÓN}

Toda Constitución contiene un estatuto de garantías y derechos fundamentales de la persona humana. Y ellos son siempre relativos, por cuanto se disfrutan y ejercitan según las leyes que los reglamentan.

El ordenamiento jurídico contempla un tratamiento diferenciado para el goce de los derechos y garantías en situaciones estables y normales de la vida en sociedad y en situaciones de emergencia, habilitando en este último caso la suspensión o limitación de los primeros. A modo ejemplificativo, cabe citar el caso de la Constitución argentina, art. 23.

\footnotetext{
${ }^{27}$ Ley No 23.098, “Hábeas Corpus”. B.O. 25/10/1984.

${ }^{28}$ Ley No 25.326, "Hábeas Data”. B.O. 02/11/2000.
} 
La emergencia no puede ser utilizada como subterfugio para convertir la República en el Leviatán de Hobbes o en un Estado de poder ilimitado o sin control. Aun durante la emergencia existen limitaciones al Estado que surgen de la misma Constitución, como por ejemplo: límites de tiempo, límites materiales, razonabilidad de las medidas y transitoriedad, esto es, mientras dure la excepción, pero sin que la excepción dure tanto que deje de ser tal y se confunda con la regla.

La transgresión de los límites jurídicos provoca lo que Kägy denomina como "desmontaje de la Constitución".

Debe tenerse especialmente en cuenta la doctrina sentada por la Corte Interamericana de Derechos Humanos en la materia, en virtud de la cual se ha establecido que, "estando suspendidas las garantías, algunos de los límites legales de la actuación del poder politico pueden ser distintos de los vigentes en condiciones normales, pero no deben considerarse inexistentes ni debe [...] entenderse que el gobierno esté investido de poderes abstractos" ${ }^{29}$ (el destacado nos pertenece).

El Estado de Derecho ha sido conmovido en su fin y su propia existencia por esta realidad de las emergencias o circunstancias de excepción que en forma ordinaria afectan a nuestro país, la región y el mundo entero. Las experiencias pasadas constituyen evidencia empírica de la tendencia de los gobiernos a suprimir las garantías, derechos y libertades de las personas. ${ }^{30}$ Todo esto constituye una cuestión delicada.

Hace más de doscientos años el Juez Marshall advertía en el paradigmático "Marbury vs. Madison" que la esencia de la libertad consiste en el derecho de todo individuo a reclamar la protección de las leyes cuando ha sido objeto de daño; que uno de los principales deberes del Estado es proveer esa protección y que, si no cumple con este imperativo, dejaría de merecer el calificativo de "gobierno de leyes" o "Estado de Derecho". ${ }^{31}$

En este orden de ideas, podemos afirmar que las garantías judiciales son constitutivas del Estado de Derecho, tanto en tiempo de normalidad como en tiempos de emergencia. Constituyen, en el pensar de Hesse, "presupuestos indispensables para la efectividad de la Constitución", 32 es decir, para que la Constitución se cumpla.

\footnotetext{
${ }^{29}$ Cfr. Corte Interamericana de Derechos Humanos (1987): “Opinión Consultiva O.C. 8/87 del 30/01/1987 - El Hábeas Corpus bajo Suspensión de Garantías (Arts. 27.2, 25.1 y 7.6 Convención Americana sobre Derechos Humanos)", párr. 25, [fecha de consulta: 23/03/2010]. Disponible en: http://www.corteidh.or.cr/ docs/opiniones/seriea_08_esp.pdf

${ }^{30}$ Cfr. Tribe, Lawrence y Gudridge, Patrick O. (2004).

${ }^{31}$ Ver Miller, Jonathan M., Gelli, María Angélica y Cayuso, Susana (1992), pp. 5-16; Haro, Ricardo (2008), pp. 271-272; Fernández Segado, Francisco (2009), pp. 62 y ss.; Balkin, Jack y LeVInSOn, Sanford (2010): http://www.yale.edu/lawweb/jbalkin/articles/whatarethefactsofmarbury1.pdf

${ }^{32}$ Citado por Risso Ferrand, Martín (2007), p. 17.
} 
$\mathrm{Al}$ respecto, Bidart Campos señala que: "durante el estado de sitio, la restricción que razonablemente pueden padecer los derechos y libertades individuales es capaz de hacer decaer paralelamente la eficacia del amparo que como garantía los tutela. Sabemos que el estado de sitio como instituto de emergencia hace viable una limitación más intensa y severa del ejercicio de algunos derechos" pero, lo que no admitimos, es "que se obture la procedencia formal del amparo, es decir, la interposición de la acción y el trámite del proceso", 33 ni que la ausencia del debido proceso legal convierta el trámite en un proceso aparente y/o coarte la efectividad de las garantías.

En cuanto al hábeas corpus, se ha dicho que:

“a) Puede interponerse durante el estado de sitio;

b) El proceso debe tramitarse con suficiente diligencia en su duración y en la amplitud probatoria;

c) El efecto será exitoso o no, según que la sentencia, ejerciendo control de razonabilidad, resuelva que la restricción de la libertad corporal ha sido arbitraria o no, subsistiendo el gravamen para la libertad del individuo a ese momento's4.

Por cuanto entendemos que las garantías "son todas aquellas seguridades y promesas que ofrece la Constitución al pueblo argentino, y a todos los hombres, de que sus derechos generales y especiales han de ser sostenidos y defendidos por las autoridades $y$ por el pueblo mismo... '35. Va de suyo que la ausencia o debilidad de las garantías aludidas dejan inermes y a veces inexistentes los derechos fundamentales que deben tutelar.

Las garantías imponen límites al poder y dentro de un Estado de Derecho protegen las libertades públicas, coadyuvan a la tutela del orden democrático y al control de constitucionalidad y control de convencionalidad ${ }^{36}$.

\subsection{Las garantías judiciales y los estados de emergencia en el derecho constitucional comparado}

Los estados de excepción y estados de emergencia han sido reconocidos por numerosas constituciones antiguas y recientes. ${ }^{37}$ Hunden sus raíces históricas en el modelo de la República Romana para situaciones de crisis, valioso antecedente para

\footnotetext{
${ }^{33}$ Bidart Campos, Germán J. (2000): Manual de la Constitución Reformada (Buenos Aires, Ediar), T. II, p. 385.

${ }^{34}$ Bidart Campos, Germán J. (2000), p. 368.

${ }^{35}$ GonZÁlez, Joaquín V., pp. 77-78.

${ }^{36}$ Ver SAGÜés, Néstor Pedro (2009).

${ }^{37}$ Cfr. Habërle, Peter, p. 292.
} 
el diseño de un sistema político de frenos y contrapesos (check and balance) en la asignación de poderes de emergencia (emergency powers) al órgano ejecutivo. ${ }^{38}$

Transitando un camino diacrónico desde aquel hito hasta los tiempos de hoy, encontramos que en el horizonte jurídico constitucional los estados de "emergencia" se encuentran previstos en los textos constitucionales de los Estados. ${ }^{39}$

Peter Habërle ${ }^{40}$ destaca una serie de preguntas fundamentales que deben responderse en el diseño de su política constitucional: ¿Quién declara el Estado de Excepción (por ejemplo, el Presidente o el Parlamento)? ¿Cuáles son las condiciones y supuestos de hecho para declararlo (por ejemplo, supuestos de emergencia interna -catástrofes, accidentes graves, peligros para la supervivencia de la democracia, etc.- y externa -defensa-)? ¿Se conforma con una cláusula general (por ejemplo, la Constitución de Weimar-art. 48-) o se resuelve a través de numerosas normas detalladas (por ejemplo, la LF alemana de 1968)? ¿Quién controla la proporcionalidad de las medidas? ¿Quién decide sobre la duración de los estados de excepción?

Cabe referirnos ahora al tratamiento específico que dispensan las leyes fundamentales a las garantías judiciales en estados de emergencia o excepción. Así, la Constitución Política de México, en su art. 29 establece expresamente que situaciones de grave peligro o conflicto, solamente el Presidente, de acuerdo con los Titulares de las Secretarías del Estado, y la Procuraduría General de la República y con aprobación del Congreso de la Nación y, en los recesos de éste, de la Comisión Permanente, podría suspender en todo el país o en un lugar determinado las garantías que fuesen obstáculo para hacer frente, rápida y fácilmente a la situación; pero deberá hacerlo por un tiempo limitado, que la suspensión se contraiga a determinado individuo.

Asimismo, cabe señalar que el amparo fue establecido en México en la Constitución del Estado de Yucatán el treinta y uno de marzo de mil ochocientos cuarenta y uno (31-03-1841), según un proyecto que elaboró el jurista mexicano Manuel Crescencio García Rejón, estableciéndose por primera vez en Latinoamérica esta vía de control de constitucionalidad de las leyes e instituyéndose en el Acta Constitutiva y de Reformas de 1847.

En Honduras, en los arts. 187 y 188 de la Constitución, se "autoriza la suspensión o restitución de derechos, en caso de invasión del territorio, perturbación

\footnotetext{
${ }^{38}$ Ackerman, Bruce (2004).

${ }^{39}$ Para un abordaje de los estados de emergencia en clave en el marco de los procesos de transición del constitucionalismo y consolidación de la Democracia en América, Europa, África y Asia, ver Mezzetti, Luca (2000).

${ }^{40}$ Cfr. Habërle, Peter, p. 292.
} 
grave de la paz, epidemia o cualquier otra calamidad, dando efectividad a la Ley del Estado de Sitio".

El art. 121 de la Constitución de Costa Rica atribuye a la Asamblea Legislativa las facultades de:

“...6) Autorizar al Poder Ejecutivo para declarar el estado de defensa nacional y para concretar la paz; 7) Suspender por votación no menos de dos tercios de la totalidad de sus miembros, en caso de evidente necesidad pública, los derechos y garantías individuales consignados en los artículos 22, 23, 24, 26, 28, 29, 30 y 37, de esta Constitución. Esta suspensión podría ser de todos o de algunos derechos y garantías, para la totalidad o parte del territorio, y hasta por treinta días, durante ella y respecto de las personas, el Poder Ejecutivo sólo podría ordenar su detención en establecimientos no destinados a ser comunes o decretar su confinamiento en lugares habitados. Deberá también dar cuenta a la Asamblea en su próxima reunión de las medidas tomadas para salvar el orden público o mantener la seguridad del Estado. En ningún caso podrán suspenderse derechos y garantias individuales no consignadas en este inciso".

En el caso, cabe destacar que los derechos y garantías afectados se refieren a los de locomoción e ingreso al país; inviolabilidad de domicilio; a la intimidad y a la libertad, y al secreto de las comunicaciones; de reunión pacífica y sin armas; derecho de acción; de libre emisión del pensamiento, y de acceso a los departamentos administrativos con propósitos de información sobre asuntos de interés público $^{41}$.

Asimismo, los arts. 10 y 48 de la Carta Fundamental precitada, prescriben:

"Artículo 10.- Corresponderá a una Sala especializada de la Corte Suprema de Justicia declarar, por mayoría absoluta de sus miembros, la inconstitucionalidad de las normas de cualquier naturaleza y de los actos sujetos al Derecho Público. No serán impugnables en esta vía los actos jurisdiccionales del Poder Judicial, la declaratoria de elección que haga el Tribunal Supremo de Elecciones y los demás que determine la ley.

Le corresponderá además:

a) Dirimir los conflictos de competencia entre los dos Poderes del Estado, incluido el Tribunal Supremo de Elecciones, asi como con las demás entidades u órganos que indique la ley.

b) Conocer de las consultas sobre proyectos de reforma constitucional, de aprobación de convenios o tratados internacionales y de otros proyectos de ley, según se disponga en la ley. Articulo 48.- Toda persona tiene derecho al recurso de hábeas corpus para garantizar su libertad e integridad personales, y al recurso de amparo para mantener o restablecer el goce de los otros derechos consagrados en esta Constitución, así como de los de carácter

${ }^{41}$ Cfr. SenZ J., Luis Felipe (2006), p. 210. 
fundamental establecidos en los instrumentos internacionales sobre derechos humanos, aplicables en la República. Ambos recursos serán de competencia de la Sala indicada en el artículo 10".

El art. 39 de la Constitución de Chile, prevé que:

"[e]l ejercicio de los derechos y garantías que la Constitución asegura a todas las personas sólo puede ser afectado en las siguientes situaciones de excepción: guerra externa o interna, conmoción interior, emergencia y calamidad pública".

El art. 40 define en seis numerales la competencia de su declaratoria, y en el art. 41 los derechos que son afectados. Asimismo dispone que:

"Una ley orgánica constitucional podrá regular los estados de excepción y facultar al Presidente de la República [...] sin perjuicio de lo establecido en los estados de emergencia $y$ de catástrofe...".

Dentro de una línea interpretativa general coincidimos con Nogueira Alcalá que, ante la existencia de situaciones excepcionales y anormales que amenazan gravemente poner en peligro inminente la subsistencia del Estado y del ordenamiento jurídico, "debe recurrirse a medidas extraordinarias, dictadas de acuerdo a las necesidades que presenta la situación, siempre que la finalidad perseguida sea coherente con los principios inherentes al Estado Democrático de Derecho en que se inserta... 'ł2. Y agrega "...el respeto por las autoridades del Estado de las normas constitucionales sobre estados de excepción, que al armonizarlas con los pactos internacionales constituye una garantía para los derechos de las personas, la que no existiría de no regularse jurídicamente las situaciones anormales que pueden superarse dentro del Estado de Derecho y del respeto de los derechos de las personas" ${ }^{3 \times 3}$.

En Perú, se encuentra previsto en el Capítulo VII, art. 137 de la Constitución Política del Perú: - Estados de excepción - estado de emergencia y estado de sitio.

"El Presidente de la República, con acuerdo del Consejo de Ministros, puede decretar, por plazo determinado, en todo el territorio nacional, o en partes de él, y dando cuentas al Congreso o a la Comisión Permanente, los estados de excepción que en este artículo se contemplan:

1. Estado de emergencia, en caso de perturbación de la paz o del orden interno, de catástrofe o de graves circunstancias que afecten la vida de la Nación. En esta eventualidad, puede restringirse o suspenderse el ejercicio de los derechos constitucionales relativos

\footnotetext{
${ }^{42}$ Nogueira Alcalá, Humberto (1997), pp. 295-296 en Fernández GonzÁlez, Miguel Ángel (octubre de 2002/marzo de 2003), p. 119.

${ }^{43}$ Ibídem.
} 
a la libertad y la seguridad personales, la inviolabilidad del domicilio, y la libertad de reunión y de tránsito en el territorio comprendidos en los incisos 9, 11 y 12 del artículo $2 y$ en el inciso 24, apartado $f$ del mismo artículo. En ninguna circunstancia se puede desterrar a nadie".

El plazo del estado de emergencia no excede sesenta días. Su prórroga requiere nuevo decreto. En estado de emergencia las Fuerzas Armadas asumen el control del orden interno si asi lo dispone el Presidente de la República.

2. Estado de sitio, en caso de invasión, guerra exterior, guerra civil, o peligro inminente de que se produzcan, con mención de los derechos fundamentales cuyo ejercicio no se restringe o suspende. El plazo correspondiente no excede de cuarenta y cinco dias. Al decretarse el estado de sitio, el Congreso se reúne de pleno derecho. La prórroga requiere la aprobación del Congreso".

$\mathrm{Al}$ respecto, resulta interesante lo resuelto por el Tribunal Constitucional de Perú ${ }^{44}$ :

b. [...] "es evidente que una lectura sistemática de la Constitución y una aplicación integral de las normas relativas a los derechos fundamentales de la persona no admiten 'zonas de indefensión', menos aún de los denominados estados de excepción previstos en el artículo 137 de la Constitución, y que siempre es permisible a un justiciable la utilización de las acciones de garantía en defensa de sus derechos básicos, asi como la actuación contralora y tuitiva del Tribunal Constitucional sobre dicho material".

Es que la normativa protectora de los derechos fundamentales de la persona humana, que está prevista, consagrada y aplicada para situaciones de normalidad en la Ley Fundamental, puede ser utilizada en aquellas circunstancias de grave peligro y deterioro social, con instrumentos destructivos de ese orden constitucional para el cual fue sancionada y asegurada. Por lo tanto, una situación de excepción, aun legislando la suspensión o limitación de algún derecho, no debe conducir a un estado de indefensión ciudadana, ya que el Estado sigue sujeto en su accionar a reglas, principios y valores justificantes de su existencia y fin para el cual fue creado, esto es, el bien común.

Por otro lado, la Constitución de la República del Paraguay en su Título III, art. 288, prescribe:

"En caso de conflicto armado internacional, formalmente declarado o no, o de grave conmoción interior que ponga en inminente peligro el imperio de esta Constitución o el funcionamiento regular de los órganos creados por ella, el Congreso o el Poder Ejecutivo

\footnotetext{
${ }^{44}$ Expte. No 2409 - 2002 - AA (2002): Tribunal Constitucional de Perú, 7 de noviembre de 2002 (Recurso Extraordinario), [fecha de consulta: 23/03/10]. Disponible en: http://www.tc.gob.pe/jurisprudencia/2002/024092002-AA.html
} 
podrán declarar el Estado de Excepción en todo o en parte del territorio nacional, por un término de sesenta (60) días como máximo. En el caso de que dicha declaración fuera efectuada por el Poder Ejecutivo, la medida deberá ser aprobada o rechazada por el Congreso dentro del plazo de cuarenta y ocho horas.

Dicho término de sesenta (60) días podrá prorrogarse por periodos de hasta treinta (30) días sucesivos, para lo cual se requerirá mayoría absoluta de ambas Cámaras.

Durante el receso parlamentario, el Poder Ejecutivo podrá decretar, por única vez, el Estado de Excepción por un plazo no mayor de treinta (30) días, pero deberá someterlo dentro de los ocho (8) días a la aprobación o rechazo del Congreso, el cual quedará convocado de pleno derecho, a sesión extraordinaria, únicamente para tal efecto".

El Decreto o la ley que declare el Estado de Excepción contendrá las razones y hechos que se invoquen para su adopción, el tiempo de su vigencia y el territorio afectado, así como los derechos que restrinja.

Durante la vigencia del Estado de Excepción, el Poder Ejecutivo sólo podrá ordenar, por Decreto y en cada caso, las siguientes medidas: la detención de las personas indiciadas de participar en algunos de esos hechos, su traslado de un punto a otro de la República, así como la prohibición o la restricción de reuniones públicas y de manifestaciones.

En todos los casos las personas indiciadas tendrán la opción de salir del país.

El Poder Ejecutivo informará de inmediato a la Suprema Corte de Justicia sobre los detenidos en virtud del Estado de Excepción y sobre el lugar de su detención o traslado, a fin de hacer posible una inspección judicial.

Los detenidos en razón del Estado de Excepción permanecerán en locales sanos y limpios, no destinados a reos comunes, o guardarán reclusión en sus propias residencias. Los traslados se harán siempre a sitios poblados y salubres.

El Estado de Excepción no interrumpirá el funcionamiento de los poderes del Estado, la vigencia de esta Constitución ni, especificamente, el hábeas corpus.

El Congreso, por mayoría absoluta de votos, podrá disponer en cualquier momento, el levantamiento del Estado de Excepción, si considerase que cesaron las causas de su declaración.

Una vez que finalice el Estado de Excepción, el Poder Ejecutivo informará al Congreso, en un plazo no mayor de cinco (5) días, sobre lo actuado durante la vigencia de aquél".

Entre los fundamentos de la exposición de motivos, en relación con la garantía constitucional del hábeas corpus, el Convencional Rodrigo Campos Cervera ${ }^{45}$ sostuvo la vigencia de esta garantía constitucional aun en Estados de excepción, por los siguientes motivos: en primer lugar, por cuanto ha tenido conocimiento que tanto en la doctrina como en algunas Constituciones, esta garantía se suspende. Cita opiniones de grandes juristas como Sánchez Viamonte, que en su libro "La

${ }^{45}$ Comisión Redactora (2000): Diario de Sesiones No 30 en la Constitución de la República del Paraguay (Asunción, Latisidata), p. 303. 
Ley Marcial y el Estado de Sitio" señalaba que la redacción del art. 23 de la Constitución argentina impone el Jubileo del Derecho, es decir, que durante la vigencia de esta circunstancia anómala, el Poder Ejecutivo tiene la posibilidad discrecional de suspender las garantías y los derechos que considere convenientes, postura que -según este autor- provocó verdaderas catástrofes jurídicas constitucionales, que hoy felizmente se habrían superado.

Y en cuanto al Paraguay, se entendía que el problema del estado de sitio no era justiciable. Por lo que no prosperaba el hábeas corpus, o no debía darse curso al mismo, lo que en época de dictadura, con una clara desviación del poder, se aplicaba no en razón del estado de sitio, sino con motivo de él.

Concluimos que ahora, con esta normativa, se establece la legitimidad de la medida, su razonabilidad, porque es la garantía específica de la libertad personal, por lo que aun en Estados de Excepción no se suspende su vigencia.

Ingresando ahora a las Constituciones europeas, cabe citar a la Constitución española en el Capítulo V -De la suspensión de derechos y libertades-art. 55, establece:

1. Los derechos reconocidos en los artículos 17, 18 apartados 2 y 3; arts. 19, 20 apartados 1, a) y d) y 5; arts. 21, 28 apartado 2, y art. 37, apartado 2, podrán ser suspendidos cuando se acuerde la declaración del estado de excepción o de sitio en los términos previstos en la Constitución. Se exceptúa de lo establecido anteriormente el apartado 3 del art. 17 para el supuesto de declaración de estado de excepción.

2. Una ley orgánica podrá determinar la forma y los casos en los que, de forma individual y con la necesaria intervención judicial y el adecuado control parlamentario, los derechos reconocidos en los arts. 17, apartado 2, y 18, apartados 2 y3, pueden ser suspendidos para personas determinadas, en relación con las investigaciones correspondientes a la actuación de bandas armadas o elementos terroristas.

La utilización injustificada o abusiva de las facultades reconocidas en dicha ley orgánica producirá responsabilidad penal, como violación de los derechos y libertades reconocidos por las leyes". (El destacado nos pertenece).

Pueden afectarse los derechos a la libertad, detención preventiva, seguridad, inviolabilidad del domicilio, secreto de las comunicaciones, de locomoción interna y de salir y entrar del territorio, de elección, residencia, emisión de pensamiento y otros.

La Constitución de los Estados Unidos de América autoriza al Presidente a que, unilateralmente, declare y mantenga el Estado de Emergencia. Tal es así, que en algún momento de su historia constitucional, se sostuvo que "anything the President says is a national emergency is a national emergency". "No se suspen-

${ }^{46}$ Cfr. Vermeule, Adrián (2007). 
derá la garantía de hábeas corpus, salvo cuando en casos de rebelión o invasión la seguridad pública así lo exija (Sección 9).

En la misma línea, la Carta Magna francesa contiene la cláusula de estados de emergencia en su art. $16^{47}$, colocando una gran cuota de poder sobre el Ejecutivo.

En una vereda distinta, las Constituciones de Europa del Este, reaccionando contra el totalitarismo de la segunda mitad del siglo XX, rechazan el unilateralismo francés, estableciendo un mayor control por parte del Parlamento. A modo ejemplificativo, cabe citar las Constituciones de Rumania, Hungría y Polonia. ${ }^{48}$

La Constitución de la Federación Rusa, faculta al Presidente para que implante de Excepción, en circunstancias y según el orden previstos por la Ley Constitucional Federal del Estado, comunicándolo inmediatamente al Consejo de la Federacion y a la Duma de Estado (art. 88). El Consejo deberá aprobar el decreto por medio del cual se declara el Estado de Excepción (art. 102.3).

En el caso de Argentina, la Constitución Nacional, en la Primera Parte -Capítulo Primero- Declaraciones, derechos y garantías, el art. 23 establece:

"En caso de conmoción interna o de ataque exterior que pongan en peligro el ejercicio de esta Constitución y de las autoridades creadas por ella, se declarará en estado de sitio la provincia o territorio donde exista la perturbación del orden, quedando suspendidas allí las garantías constitucionales. Pero durante esta suspensión no podrá el presidente de la República condenar por si ni aplicar penas. Su poder se limitará en tal caso respecto de las personas, a arrestarlas o trasladarlas de un punto a otro de la Nación, si ellas no prefieren salir fuera del territorio argentino".

El art. 75 inc. 29 de la Constitución Nacional faculta al Congreso Nacional para:

"Declarar el estado de sitio en uno o varios puntos de la Nación en caso de conmoción interior, y aprobar o suspender el estado de sitio declarado, durante un receso, por el Poder Ejecutivo".

\footnotetext{
${ }^{47}$ Constitución de Francia, art. 16: "Cuando las instituciones de la República, la independencia de la Nación, la integridad de su territorio o el cumplimiento de sus compromisos internacionales estén amenazados de manera grave o inmediata y el funcionamiento regular de los poderes públicos constitucionales esté interrumpido, el Presidente de la República tomará las medidas exigidas por tales circunstancias, previa consulta oficial con el Primer Ministro, los Presidentes de las asambleas y el Consejo Constitucional.

Informará de ello a la Nación por medio de un mensaje.

Dichas medidas deberán estar inspiradas por la voluntad de garantizar a los poderes públicos constitucionales, en el menor plazo, los medios para cumplir su misión. El Consejo Constitucional será consultado sobre ello. El Parlamento se reunirá de pleno derecho.

No podrá ser disuelta la Asamblea Nacional durante el ejercicio de los poderes extraordinarios".

${ }^{48}$ Cfr. Ackerman, Bruce (2004).
} 
La Constitución Nacional ha previsto situaciones de emergencia, a saber:

- Conmoción interior (que pone en grave peligro a la Ley Fundamental y autoridades que ella creó (arts. 23 y 75 inc. $29 \mathrm{CN}$ referenciados supra)

- Ataque exterior (guerra o invasión desde el interior (arts. 6, 75 inc. 25 y 99 inc. $15 \mathrm{CN}$ )

- Alteración de la forma republicana de gobierno en las provincias (art. $5 \mathrm{CN}$ )

- Legislación delegada del Poder Legislativo al Poder Ejecutivo - emergencia pública (art. $76 \mathrm{CN}$ )

- Defensa, seguridad común y bien general del Estado (el Congreso asume el poder conservado de las provincias, creando impuestos internos directos (art. 75 inc. $2 \mathrm{CN}$ ) o establece asignaciones específicas a impuestos coparticipables (art. 75 inc. $3 \mathrm{CN}$ )

- Intervención federal (art. $6 \mathrm{CN}$ )

Cabe precisar que, si bien contempla situaciones excepción, no posee reglas que permitan determinar sus efectos y alcances.

En razón de ello, la doctrina de la Emergencia se ha ido construyendo como fruto de la labor pretoriana de nuestra Corte Suprema de Justicia de la Nación, ${ }^{49}$ importando la doctrina judicial de los Estados Unidos.

En concreto, ha establecido que:

a) la emergencia puede ser declarada por el Poder Legislativo o por el Ejecutivo;

b) se admite la limitación de los derechos, conforme las siguientes pautas:

- La suspensión o restricción de los derechos debe ser temporal;

- No puede llevar consigo el aniquilamiento de los derechos;

- Debe someterse a un test de razonabilidad de medios-fines.

Para justificar constitucionalmente todo esto, apunta Sagüés, la Corte ha recurrido a menudo a la tesis de la "doble lectura" de la Constitución, en virtud de la cual: a) el goce de los derechos no es igual en momentos de normalidad que en momentos de emergencia; b) los poderes estatales de excepción son los mismos que siempre posee el Congreso o el Presidente, pero ejercidos de modo pleno y a veces diverso que el practicado en circunstancias ordinarias, ya que "los acontecimientos extraordinarios justifican remedios extraordinarios". ${ }^{50}$

\footnotetext{
${ }^{49}$ Desde principios del siglo XX, casi todas las décadas la Corte Suprema de Justicia de la Nación ha dictado, por lo menos, un pronunciamiento sobre emergencia y su relación con la Constitución. (Cfr. FerReYrA, Raúl Gustavo (2003). Algunos de los fallos más destacados son: "Ercolano c. Lanteri" y "Horta c. Harguindeguy" (1922), "Cine Callao" (1960) (Sup. Emerg Económ. y Teoría del Derecho (2003) agosto, pp. 75, 84, 142), "Peralta"(1991) (La Ley, 1991-C, 158) "Irizar c. Provincia de Misiones"(1997) (La Ley, 1997-A, 666), "Smith" (2002) (La Ley, 2002-A, 770; 2002-C, 148) y "Provincia de San Luis"(2003) (La Ley, 2003-B, 537; 2003-C, 38; 2003-C, 228; Sup. Esp. 2003/03/06, p. 4). Cfr. CAYuso, Susana (2003).
}

${ }^{50}$ SAGUÉs, Néstor Pedro (2004). 
Esta doctrina, agrega el jurista rosarino, resulta algo artificiosa y nos plantea la interrogante de si, por encima de la fraseología empleada ¿se propone una "doble lectura" de la Constitución o se trata en definitiva de "dos constituciones": una para los instantes de normalidad, otra para los cada vez más frecuentes largos segmentos de emergencia, donde impera el estado de necesidad y su producto jurídico, el derecho de necesidad?

Coincidimos con Badeni, en que las normas de emergencia pueden limitar, con mayor intensidad que en los momentos de normalidad, los derechos y garantías constitucionales, pero dentro de los límites establecidos por los arts. 19, 28, 29 y 31 de la Ley Fundamental. Lo contrario, implica un proceso de desconstitucionalización del Estado de Derecho, ${ }^{51}$ que dispararía al corazón de la vigencia de la Constitución Nacional.

En este orden de ideas, resulta necesario indagar la justificación constitucional que tienen la selección y elección de medidas para hacer frente a la emergencia. Nuevamente cobra relevancia el grado de relación causal entre medida y fin específicamente buscado y grado de adecuación, necesidad y proporción de aquél respecto del sacrificio que impone a los derechos y garantías de todos y cada uno de los integrantes de la sociedad a la que va dirigida la normativa. Tales extremos apuntan a la razonabilidad de la medida ${ }^{52}$.

Finalmente, en cuanto a la administración del servicio de justicia en Argentina- de nuestros días-, cabe precisar que las garantías constitucionales, entre ellas el hábeas corpus y del amparo, se pueden volver ilusorias en una situación de emergencia nacional ${ }^{53}$, por cuanto la sobreabundancia de causas y la superpobla-

\footnotetext{
${ }^{51}$ Cfr. BADENi, Gregorio (2008).

${ }^{52}$ Cfr. Cayuso, Susana (2003).

${ }^{53}$ A partir del año 2001, Argentina se encuentra en una situación de emergencia nacional dispuesta por la Ley Nac. 25.561, "Emergencia Pública y Reforma del Régimen Cambiario”, B.O. (Número extraordinario) 07/01/2002 - ADLA 2002 - A, 44 - DT 2002 - A, 314. Incluso, a la fecha en forma anual se dicta la ley correspondiente de prórroga de esta situación de emergencia.

La referida situación de emergencia abarca la emergencia pública y la reforma del régimen cambiario - Modificación de la ley de convertibilidad - Reestructuración de deudas con el sector financiero - Creación de un derecho de exportación de hidrocarburos - Consignación y pago en pesos de saldos deudores de titulares de tarjeta de crédito - Se dejan sin efecto las cláusulas de ajuste en divisas extranjeras y las cláusulas indexatorias en los contratos celebrados bajo normas de derecho público - Regulación de prestaciones dinerarias pactadas en dólares u otra moneda extranjera - Canje de títulos nacionales y provinciales - Regulación transitoria de precios de insumos, bienes y servicios críticos - Suspensión de los despidos sin causa justificada por el plazo de 180 días - Recurso de apelación ante la Corte Suprema de Justicia de la Nación contra medidas cautelares que afecten el desenvolvimiento de actividades esenciales del Estado - Creación de la Comisión Bicameral de Seguimiento - Suspensión de la aplicación de las leyes 25.466 y 25.557 - Modificación del dec. 1570/2001 y de las leyes 17.454 (Código Procesal Civil y Comercial de la Nación - t. o. 1981) y 23.928.
} 
ción de los presos en las cárceles constituyen los factores decisivos que colapsan al Poder Judicial y ello tiene una directa incidencia en la efectividad de las garantías del debido proceso y defensa en juicio (art. $18 \mathrm{CN}$ ). ${ }^{54}$

\subsection{LAS GARANTÍAS JUDICIALES Y LOS ESTADOS DE EMERGENCIA \\ EN LOS TRATADOS DE DERECHOS HUMANOS}

En este apartado del trabajo, pretendemos abordar las garantías judiciales en los estados de emergencia a la luz de las previsiones contenidas en los tratados sobre derechos humanos.

Previo ingresar al tratamiento específico, advertimos que la tendencia moderna en el horizonte jurídico internacional consiste en reconocer, a través de la Constitución, la supralegalidad internacional de los tratados de derechos humanos o, mejor aún, su rango constitucional.

Los Estados que han optado por esta alternativa, se encuentran entre los más avanzados del mundo en este punto, transitando de un concepto clásico de Constitución a un concepto moderno de "Bloque de Constitucionalidad". No podemos soslayar las palabras de Cea Egaña ${ }^{55}$, quien destaca que se ve facilitada la retroalimentación entre la Carta Fundamental y los tratados sobre derechos humanos, por el hecho de que ambos sean igualmente afines en punto a que tratan sobre la dogmática, el reconocimiento y promoción de los derechos y de la dignidad de la persona.

En Argentina, por ejemplo, mediante el art. 75 inc. 22 de la Carta Fundamental, se invistió de jerarquía constitucional a una serie de tratados sobre derechos humanos y se diseñó un mecanismo para elevar al mismo orden de prelación a otros tratados de derechos humanos, sin necesidad de reformar la Constitución.

En relación a Chile, Humberto Noguerira Alcalá es tributario de la existencia del "Bloque de Constitucionalidad Chileno" ${ }^{\text {, }}$, precisa que "[el] orden constitucional

\footnotetext{
54 "El sostenido aumento de los casos judiciales, penales y de todo tipo, afligen hoy a la sociedad, prisionera entre el miedo y la impotencia. También la Justicia padece la situación, atravesada por realidades cada vez más dificiles de gobernar. Argentina produce más de 4.000 .000 de conflictos que se judicializan por año. De ellos, una cifra cercana a la mitad, se trata de asuntos penales. Con esta cantidad de casos, no puede convivir la población ni el sistema judicial, se haga con él lo que se haga. Las cárceles en todo el país están superpobladas, las leyes penales fueron endurecidas y la situación no cambia". (FEMING, Abel y LODEIRO, Fernando -presidente y secretario de la Federación Argentina de la Magistratura-: "Federación Argentina de la Magistratura. Justicia y Seguridad. Qué proponemos hacer", [fecha de consulta: 01/07/09]. Disponible en: http://www.fam.org.ar/notas. asp?id=306

55 Cea Egaña, José Luis (1997).

${ }^{56}$ Sobre el contenido del Bloque Constitucionalidad Chileno ver Zapata Larraín, Patricio (2008): Justicia Constitucional. Teoría y Práctica en el Derecho Chileno y Comparado (Chile, Editorial Juridica de Chile), p. 307.
} 
[chileno] de derechos esenciales o humanos, [está] constituido por los derechos expresamente asegurados en el texto de la Carta Fundamental, los cuales se complementan, enriquecen y fortalecen con los enunciados normativos de tratados internacionales que contribuyen a delimitar mejor, a proteger más, a fortalecer los derechos y garantías de los derechos escenciales, fundamentales o humanos, como asimismo, por los eventuales derechos implícitos ${ }^{257}$.

Otros ejemplos que pueden citarse son: Grungezets de Alemania (Art. 25), Constitución de Francia (Art. 55), Constitución de Portugal (Art. 16.2), Constitución de España (Art. 10.2), Constitución de El Salvador (Arts. 144 y 149), Constitución de Colombia (Art. 93), etc.

En todos los casos el texto constitucional y los tratados deberán interpretarse armónicamente. No debe efectuarse jamás una hermenéutica de modo tal que queden frente a frente los derechos y deberes enumerados para que se destruyan recíprocamente, sino procurarse su armonía dentro del espíritu que le dio vida ${ }^{58}$.

Asimismo, deberán tener especialmente en cuenta la jurisprudencia y opiniones consultivas de los órganos del sistema protección de derechos humanos del que formen parte.

Ingresando al análisis particular de los tratados, corresponde, en primer término, referirnos a la Declaración Universal de los Derechos Humanos. Este instrumento internacional contiene un mandato fuerte de tutela respecto de los derechos y garantías fundamentales, estableciendo requisitos para su restricción. En concreto, en su art. 29. 2 prevé que:

"en el ejercicio de sus derechos y disfrute de sus libertades toda persona estará solamente sujeta a las limitaciones establecidas por la ley, con el único fin de asegurar el reconocimiento y el respeto de los derechos y libertades de los demás, y de satisfacer las justas exigencias de la moral, el orden público y del bienestar general en una sociedad democrática".

Se considera que la libertad, la justicia y la paz en el mundo tienen por base el reconocimiento de la dignidad intrínseca y de los derechos iguales e inalienables de todos los miembros de la familia humana. Considera esencial que todos los derechos humanos sean protegidos por un régimen de Derecho; que los Estados miembros se comprometan a asegurar, en cooperación con la Organización de las Naciones Unidas, el respeto universal y efectivo de los derechos y libertades fundamentales del hombre; y que una concepción común de estos derechos y libertades es de mayor importancia para el pleno cumplimiento de dicho compromiso.

\footnotetext{
${ }^{57}$ Nogueira Alcalá, Humberto (2009).

${ }^{58}$ Conf. Moncayo, Guillermo R. (1998), p. 94.
} 
Nos proporciona un techo ideológico y marco axiológico a la luz del cual se puede realizar una lectura de las garantías judiciales en situaciones de emergencia, consistente en limitar al mínimo las restricciones a aquéllas, velando siempre por la tutela efectiva de los derechos fundamentales.

Debemos resaltar que a la Convención Americana sobre Derechos Humanos $(\mathrm{CADH})$ o Pacto de San José de Costa Rica, en el Capítulo IV Suspensión de garantías, interpretación y aplicación, artículo 27, establece:

"1. En caso de guerra, de peligro público o de otra emergencia que amenacen la independencia o seguridad del Estado Parte, éste podrá adoptar disposiciones que, en la medida y por el tiempo estrictamente limitados a las exigencias de la situación, suspendan las obligaciones contraidas en virtud de esta Convención, siempre que tales disposiciones no sean incompatibles con las demás obligaciones que les impone el derecho internacional y no entrañen discriminación alguna en motivo de raza, color, sexo, idioma, religión $u$ origen social".

"2. La disposición precedente no autoriza la suspensión de los derechos determinados en los siguientes artículos: 3 (Derecho al Reconocimiento de la Personalidad Jurídica); 4 (Derecho a la vida); 5 (Derecho a la Integridad Personal); 6 (Prohibición de la Esclavitudy Servidumbre); 9 (Principio de la Legalidad y de la Retroactividad);... 12 (Libertad de Conciencia y de Religión); ... 17 (Protección a la Familia); 18 (Derecho al Nombre); 19 (Derecho del Niño); 20 (Derecho de la Nacionalidad); ...23 (Derechos Politicos), ni de garantias judiciales indispensables para la protección de tales derechos".

"3. Todo Estado Parte que haga uso del derecho de suspensión deberá informar inmediatamente a los demás Estados Partes en la presente Convención, por conducto del Secretario General de la Organización de los Estados Americanos, de las disposiciones cuya aplicación haya suspendido, de los motivos que hayan suscitado la suspensión y de la fecha en que haya dado por terminada tal suspensión".

Sobre este punto nos referimos infra.

Por otra parte, el Pacto Internacional de Derechos Civiles y Políticos contiene una cláusula de emergencia en su artículo 4, que reza:

"1.En situaciones excepcionales que pongan en peligro la vida de la nación y cuya existencia haya sido proclamada oficialmente, los Estados Parte en el presente Pacto podrán adoptar disposiciones que en la medida estrictamente limitada a las exigencias de la situación suspendan obligaciones contraidas en virtud de este Pacto, siempre que tales disposiciones no sean incompatibles con las demás obligaciones que les impone el Derecho Internacional y no entrañen discriminación alguna fundada únicamente en motivos de raza, color, sexo, idioma, religión u origen social";

"2. La disposición precedente no autoriza suspensión alguna de los artículos $6^{\circ}, 7^{\circ}, 8^{\circ}$ (párrafos 1 y 2), 11, 15, 16 y 18". 
“3. Todo Estado Parte en el presente Pacto que haga uso del derecho de suspensión deberá informar inmediatamente a los demás Estados Parte en el presente Pacto, por conducto del Secretario General de las Naciones Unidas de las disposiciones cuya aplicación haya suspendido y de los motivos que hayan suscitado tal suspensión. Se hará una nueva comunicación por el mismo conducto en la fecha en que se haya dado por terminada tal suspensión".

Interpretando dicha norma, el Comité de Derechos Humanos de Naciones Unidas ha resaltado, en su Observación General sobre el art. 4 del Pacto Internacional de Derechos Civiles y Políticos, que las medidas dispuestas en situaciones de emergencia están limitadas a lo estrictamente requerido por las exigencias de la situación en particular, lo que refiere tanto a su duración, como a su ámbito geográfico y al alcance material del estado de emergencia y de las medidas de derogación dispuestas en consecuencia ${ }^{59}$.

Entrando al análisis de los tratados internacionales enunciados, en cuanto a los derechos fundamentales en los llamados "estados de excepción", según la orientación del Derecho Internacional de los Derechos Humanos, podemos afirmar que se basan en los siguientes principios:

- De proclamación: porque el Estado debe dar a conocer previamente y en forma general a la sociedad de que se ha producido una grave situación en su seno, que lo obliga a producir la declaración.

- De proporcionalidad: por cuanto las medidas que implemente el Estado deberán corresponderse con el peligro real, actual o inminente que debe conjurar.

- De notificación: ya que debe notificar el Estado la declaración de excepción a la Organización de Estados Americanos y a la Organización de las Naciones Unidas.

- De temporalidad: en cuanto debe atender lo provisorio del tiempo de vigencia del estado de excepción.

- De intangibilidad: de "ciertos derechos humanos que busca dotar de protección aun en casos de excepción a un núcleo de derechos fundamentales vinculados a los valores esenciales de la persona humana, su dignidad e igualdad, y aspectos relacionados con su vida, su integridad personal, su seguridad, y su desarrollo integral'60.

Una mirada responsable sobre las normas analizadas, constitucionales o de convenios internacionales, nos obliga a prever lícitamente mecanismos a los que los poderes públicos de los Estados, atiendan en situaciones de excepción. Más

\footnotetext{
${ }^{59}$ Comité de Derechos Humanos (2001): CCPR/C/21/Rev.1/Add.11, 31 de agosto de 2001, Observación General No 29: Estados de Emergencia, [fecha de consulta: 23/03/10]. Disponible en: www.unhchr.ch

${ }^{60}$ Menéndez, Florentín (2004), p. 137.
} 
aún, que puedan válidamente justificar la suspensión o restricción de derechos y libertades: ante invasiones de territorios soberanos, guerras en su consecuencia, graves conmociones internas que comprometan la paz de la sociedad y grandes desastres producidos por la naturaleza, como terremotos y epidemias generalizadas imprevisibles.

El Estado actual, en su derecho interno, aunque no en todos, prevé la necesidad de suspender o restringir libertades y garantías de sus ciudadanos con medidas excepcionales, con el fin de preservar las integridad y estabilidad social a los que se suele denominar "emergencia", "de guerra", "de sitio", de "conmoción interior", "de catástrofe", etc., por haberse perforado la normalidad del Estado de Derecho.

En estos casos, hay que distinguir el alcance de las medidas de suspensión o de restricción.

- Suspensión de garantías: "situación anormal en que, por motivos de orden público, quedan temporalmente sin vigencia algunas de las garantias constitucionales". ${ }^{61}$

- Restricción: "reducir a menores límites". ${ }^{62}$ Lo que implica una disminución en los derechos y libertades.

\section{SisTEMA INTERAMERICANO DE DERECHOS HUMANOS}

5.1. Las garantias judiciales en situaciones de emergencia en los pronunciamientos - contenciosos y consultivos - de la Corte Interamericana de Derechos Humanos

La CIDH es un órgano judicial con autonomía funcional, creada por la Convención Americana sobre Derechos Humanos, con el fin de interpretar y aplicar sus normas. Ejerce una doble competencia: consultiva y contenciosa, que complementa al derecho interno de sus Estados signatarios para proteger los derechos humanos.

$\mathrm{Al}$ respecto, la $\mathrm{CADH}$ prescribe en su artículo 62.1, que:

"Todo Estado Parte puede, en el momento del depósito de su instrumento de ratificación o adhesión de esta Convención o en cualquier momento posterior, declarar que reconoce como obligatoria de pleno derecho y sin convención especial, la competencia de la Corte sobre todos los casos relativos a la interpretación o aplicación de esta Convención". 2 [...] 3. "La Corte tiene competencia para conocer de cualquier caso relativo a la interpretación y aplicación de las disposiciones de esta Convención que le sea sometido siempre que los Estados

\footnotetext{
${ }^{61}$ Diccionario de la Real Academia Española, ob. cit.

${ }^{62}$ Ibídem.
} 
Partes en el caso hayan reconocido o reconozcan dicha competencia, ora por la declaración especial como se indica en los incisos anteriores, ora por convención especial". ${ }^{3}$

Cabe destacar que a los Estados Parte les corresponde ejercer la protección de los derechos humanos, según lo ordenado en sus propias Constituciones Fundamentales, sus leyes y lo dispuesto en el artículo 1 de dicha Convención, que expresa:

"Capitulo I - Enumeración de Deberes - Artículo 1 - Obligación de respetar los derechos humanos.

1. Los Estados Parte en esta Convención se comprometen a respetar los derechos y libertades reconocidos en ella y a garantizar su libre y pleno ejercicio a toda persona que esté sujeta a su jurisdicción, sin discriminación alguna, por motivos de raza, color, sexo, idioma, religión, opiniones politicas o de cualquier otra indole, origen nacional o social, posición económica, nacimiento o cualquier otra condición social.

2. Para los efectos de esta Convención, persona es todo ser humano".

La Convención Americana de Derechos Humanos protege estos derechos, en sus artículos 3 a 25, complementándose por el "Protocolo Adicional a la Convención Americana en materia de Derechos Económicos, Sociales y Culturales" (Protocolo de San Salvador, artículos 8 y 11, por la Convención Interamericana sobre Desaparición Forzada de Personas, Artículo XIII, y según la interpretación de la Corte en su jurisprudencia por la Convención Interamericana para Prevenir y Sancionar la Tortura).

En forma pacífica, la Corte viene sustentando que toda norma sea constitucional, legal o convencional, en lo referente a la materia de independencia e imparcialidad judicial, deben ser obedecidas en los diversos procedimientos judiciales, sean de naturaleza administrativa, penal, laboral, civil, etc., que resuelvan cuestiones de derechos humanos, por cuanto la garantía de la independencia de los jueces y de la corporación judicial, constituye el sustento del debido proceso.

Tanto las opiniones consultivas como las sentencias de la Corte, se apoyaron siempre en lo prescripto en los artículos 8.1. y 25, en concordancia con lo preceptuado en los arts. 1.1. y 2 de dicha Convención.

El artículo 8.1. establece que:

"Toda persona tiene derecho a ser oída, con las debidas garantías y dentro de un plazo razonable, por un juez competente, independiente e imparcial, establecido con anterioridad en la sustanciación de cualquier acusación penal formulada contra ella o para la

${ }^{63}$ Convención Americana sobre Derechos Humanos (Pacto de San José de Costa Rica), firmada en la ciudad de San José de Costa Rica el 22/XI/1969. Aprobada por la República Argentina, según la Ley N²3.054 (B.O. 27/III/1984). 
determinación de sus derechos y obligaciones de orden civil, laboral, fiscal o de cualquier otro carácter".

El artículo tutela el debido proceso legal y defensa en juicio como una garantía judicial necesaria y en iguales condiciones para las partes en el proceso que conlleva la actuación independiente e imparcial de los jueces.

Alirio Abreu Burelli ${ }^{64}$ analiza al respecto una opinión consultiva de la Corte, que, como todas, es vinculante para el Estado que la solicita, a saber:

"para alcanzar sus objetivos el proceso debe reconocer y resolver los factores de desigualdad de quienes son llevados ante la justicia. Es asi como se atiende el principio de igualdad ante la ley y los tribunales y la correlativa prohibición de discriminación. La presencia de condiciones de desigualdad real obliga a adoptar medidas de compensación que contribuyan a reducir o eliminar los obstáculos y deficiencias que impidan o reduzcan la defensa eficaz de los propios intereses. Si no existieran esos medios de compensación, ampliamente reconocidos en diversas vertientes del procedimiento, dificilmente se podría decir que quienes se encuentran en condiciones de desventaja disfrutan de un verdadero acceso a la justicia y se benefician de un debido proceso legal en condiciones de igualdad con quienes no afrontan esas desventajas' 65 .

No menos importante, en momentos normales como anormales, es la aplicación del artículo 25 de la Convención, en cuanto dispone que:

"1. Toda persona tiene derecho a un recurso sencillo y rápido o a cualquier otro recurso efectivo ante los jueces o tribunales competentes, que la ampare contra actos que violen sus derechos fundamentales reconocidos por la Constitución, la ley o la presente Convención, aun cuando tal violación sea cometida por personas que actúen en ejercicio de sus funciones oficiales.

2. Los Estados partes se comprometen:

a) A garantizar que la autoridad competente prevista por el sistema legal del Estado decidirá sobre los derechos de toda persona que interponga tal recurso;

b) A desarrollar las posibilidades de recurso judicial, y

c) A garantizar el cumplimiento, por las autoridades competentes, de toda decisión en que se haya estimado procedente el recurso".

La falta de garantía efectiva de un recurso efectivo, contra la conculcación de derechos protegidos por la Convención hace transgredir al Estado, por cuanto este medio no fue idóneo para evitar la violación de los derechos humanos.

${ }^{64}$ Burelli, Alirio Abreu (2007), p. 642.

${ }^{65}$ Corte Interamericana de Derechos Humanos (1999): "Opinión Consultiva OC 16 (octubre 1999)” y Casos:

"Comunidad indígena Jakie Axa", 17 de junio de 2005; "Herrera Ulloa", Sentencia de 2 de julio de 2004. 
La Opinión consultiva de la Corte, se pronunció al respecto en los siguientes términos:

"no pueden considerarse efectivos aquellos recursos que, por las condiciones generales del pais o incluso por las circunstancias particulares de un caso dado, resulten ilusorios. Ello puede ocurrir, por ejemplo, cuando su inutilidad haya quedado demostrada por la práctica, porque el Poder Judicial carezca de la independencia necesaria para decidir con imparcialidad o porque falten los medios para ejecutar sus decisiones; por cualquier otra situación que configure un cuadro de denegación de justicia, como sucede cuando se incurre en un retardo injustificado en la decisión; o por cualquier causa no se permite al presunto lesionado el acceso al recurso judicial" 66 .

La independencia del juez y el órgano judicial, fue vinculada por la Corte con la validez y eficacia de las distintas garantías judiciales en Estados de Emergencia, como el de suspender las garantías en estos momentos anormales y, por cierto, a la obligación insoslayable de todo Estado de poner al alcance de los justiciables los recursos pertinentes.

En el tema bajo examen, la opinión consultiva de la Corte, al considerar el hábeas corpus bajo suspensión de garantías (artículos 27.2., 25.1. y 7.6. de la $\mathrm{CADH})$, entendió que:

"las garantias deben ser no sólo indispensables sino judiciales. Esta expresión no puede referirse sino a medios judiciales idóneos para la protección de tales derechos, lo cual implica la intervención de un órgano judicial independiente e imparcial, apto para determinar la legalidad de las actuaciones que se cumplen dentro del estado de excepción ${ }^{\prime 67}$.

La Corte agregó que la suspensión de garantías, como asimismo, la declaración de estados de emergencia, en momentos de gran peligro público, guerras $\mathrm{u}$ otras emergencias, se debe remitir al artículo 27 de la Convención. ${ }^{68} \mathrm{Y}$, si se

\footnotetext{
${ }^{66}$ Corte Interamericana de Derechos Humanos (1987): “Opinión Consultiva OC 9/87”, ob. cit.; Casos: "Niños de la Calle" Sentencia de 19-11-99; Tribunal Constitucional, Sentencia de 31-01-00, citado por Burelli, Alirio Abreu, ob. cit., p. 643.

${ }^{67}$ Corte Interamericana de Derechos Humanos (1987): “Opinión Consultiva OC 9/87...”, ob. cit.

${ }^{68}$ Artículo 27 de la Convención Americana de Derechos Humanos -Suspensión de Garantías-.

1. En caso de guerra, de peligro público o de otra emergencia que amenace la independencia o seguridad del Estado parte, éste podrá adoptar disposiciones que, en la medida y por el tiempo estrictamente limitados a las exigencias de la situación, suspendan las obligaciones contraídas en virtud de esta Convención, siempre que tales disposiciones no sean incompatibles con las demás obligaciones que les impone el derecho internacional y no entrañen discriminación alguna fundada en motivos de raza, color, sexo, idioma, religión u origen social.

2. La disposición precedente no autoriza la suspensión de los derechos determinados en los siguientes artículos: 3 (Derecho al Reconocimiento de la Personalidad Jurídica); 4 (Derecho a la Vida); 5 (Derecho
} 
decidió en legal forma suspender las garantías, esta circunstancia debe evitar sobrepasar el nivel de lo muy necesario, resultando en consecuencia ilegal toda actuación de los poderes públicos que desborde aquellos límites que deben estar precisados y señalados en las disposiciones que decretan el estado de excepción. "Los procedimientos de hábeas corpus y de amparo son aquellas garantías judiciales indispensables para la protección de los derechos humanos, no susceptibles de suspensión, según lo dispuesto en el artículo 27.2 de la Convención”. Y son aquéllas "a las que se refiere expresamente en los artículos 7.6. y 25.1., consideradas dentro del marco y según los principios del artículo 8, y también los inherentes a la preservación del Estado de Derecho, aun bajo la legalidad excepcional que resulta de la suspensión de garantías'69.

Complementariamente a la doctrina sentada y aludida precedentemente, la Corte declaró:

"La Corte examinará en primer lugar que son de conformidad con la Convención: las garantías judiciales indispensables a las que alude el artículo 27.2. de la misma. A este respecto, en anterior ocasión, la Corte ha definido, en términos generales, que por tales garantías deben entenderse aquellos procedimientos judiciales que ordinariamente son idóneos para garantizar la plenitud del ejercicio de los derechos y libertades a que se refiere dicho artículo (27.2.) y cuya supresión o limitación pondrá en peligro esa plenitud [...]". Asimismo subrayó que el carácter judicial de tales medios "implica la intervención de un órgano judicial independiente e imparcial, apto para determinar la legalidad de las actuaciones que se cumplan dentro del estado de excepción". ${ }^{70}$

La preocupación actual por los estados de emergencia o excepción en la región, sean estados de sitio, de guerra u otros, es más significativa y sensible en nuestros juristas, pues su aplicación fue aprovechada de múltiples modos para violar los derechos humanos. Así lo destaca Héctor Gros Espiell171, por cuanto "muchos golpes de Estado y dictaduras latinoamericanas se valieron de los estados de emergencia para

a la Integridad Personal); 6 (Prohibición de la Esclavitud y Servidumbre); 9 (Principio de Legalidad y de Retroactividad); 12 (Libertad de Conciencia y de Religión); 17 (Protección a la Familia); 18 (Derecho al Nombre); 19 (Derechos del Niño); 20 (Derecho a la Nacionalidad), y 23 (Derechos Políticos), ni de las garantías judiciales indispensables para la protección de tales derechos.

3. Todo Estado parte que haga uso del derecho de suspensión deberá informar inmediatamente a los demás Estados partes en la presente Convención, por conducto del Secretario General de la Organización de los Estados Americanos, de las disposiciones cuya aplicación haya suspendido, de los motivos que hayan suscitado la suspensión y de la fecha en que haya dado por terminada tal suspensión.

${ }^{69}$ Burelli, Alirio Abreu, p. 644.

${ }^{70}$ Opinión Consultiva OC 9/87 de 06-10-87.

${ }^{71}$ Gros Espiell, Héctor (1991), p. 367. 
establecerse o mantenerse. Los estados de excepción en América Latina y las repercusiones que han tenido siempre en los derechos humanos explica la razón por la cual la cuestión ha sido objeto de regulación internacional (artículo 4 del Pacto de Derechos Civiles y Políticos de las Naciones Unidas y artículo 27 de la Convención Americana sobre Derechos Humanos) mediante normas que aseguren su control, su proporcionalidady temporalidad y la existencia de algunos derechos humanos y garantías fundamentales, que no pueden suspenderse durante esos estados de emergencia".

La Corte Interamericana se ha pronunciado en distintas oportunidades sobre las denominadas garantías judiciales, entendiendo a los recursos judiciales que pueden utilizarse para hacer valer el ejercicio de un derecho, pero señaló que su empleo (de garantías judiciales), al aludir a los derechos contenidos en el artículo 8 de la $\mathrm{CADH}$, a veces produce confusión, atento a que la norma "no es un recurso propiamente dicho". ${ }^{72}$

El artículo 8 referenciado, enmarca el concepto de "debido proceso legal o derecho de defensa en juicio", estableciendo las condiciones necesarias para garantizar una adecuada defensa judicial.

En suma, de una lectura armónica y sistemática de las normas, se colige que la $\mathrm{CADH}$ al momento de regular las situaciones de emergencia, impone dos límites al Estado:

1. Sustantivo: insuspendibilidad de un listado de derechos (art. 27.1).

2. Adjetivo: insuspendibilidad de las garantías indispensables para la protección de ellos.

La Corte, en ejercicio de su competencia consultiva, se pronunció con mayor profundidad frente al requerimiento de Uruguay acerca de "a) la determinación de cuáles son 'esas garantías judiciales indispensables', y b) la relación del art. 27.2, en lo pertinente, con los arts. 25 y 8 de la Convención Americana”. En concreto, ha señalado que las garantías judiciales indispensables a las que se refiere el art. 27.2 de la CADH son:

- El hábeas corpus (art. 7.6), el amparo, o cualquier otro recurso efectivo ante los jueces o tribunales competentes (art. 25.1), destinado a garantizar el respeto a los derechos y libertades cuya suspensión no está autorizada por la misma Convención.

- Aquellos procedimientos judiciales, inherentes a la forma democrática representativa de gobierno (art. 29.c)), previstos en el derecho interno de los Estados Partes como idóneos para garantizar la plenitud del ejercicio de los derechos a que

\footnotetext{
${ }^{72}$ Corte Interamericana de Derechos Humanos (1987): Opiniones Consultivas OC 8/87 de 30-01-87 y OC 9/87 de 06-10-87.
} 
se refiere el artículo 27.2 de la Convención y cuya supresión o limitación comporte la indefensión de tales derechos. ${ }^{73}$

Asimismo, ha precisado que dichas garantías judiciales deben ejercitarse dentro del marco y según los principios del debido proceso legal, recogidos por el artículo 8 de la Convención. Huerta Guerrero ${ }^{74}$ resumió los derechos que integran el debido proceso del art. 8 de la $\mathrm{CADH}$, en:

- Acceso a la justicia (artículo 8.1.);

- Derecho a un tribunal competente, independiente e imparcial (artículo 8.1.);

- Derecho al plazo razonable de duración de un proceso (artículo 8.1);

- Presunción de inocencia (artículo 8.2);

- Derecho de defensa, el cual comprende:

a) derecho del inculpado a ser asistido gratuitamente por un traductor o intérprete (artículo 8.2.a);

b) derecho del inculpado a la comunicación previa y detallada de la acusación formulada (artículo 8.2.b.);

c) concesión al inculpado del tiempo y de los medios adecuados para la preparación de su defensa (artículo 8.2.c);

d) derecho del inculpado de defenderse por sí mismo o a través de un defensor de su elección o nombrado por el Estado (articulos 8.2. dy e);

e) derecho del inculpado a comunicarse libre y privadamente con su defensor (artículo 8.2.d.);

f) derecho de defensa del inculpado respecto a los testigos y peritos (artículo 8.f);

- Derecho a recurrir el fallo ante juez o tribunal superior (art. 8.2.h);

- Derecho a no ser obligado a declarar contra si mismo ni a declararse culpable y declarar sin coacción de naturaleza alguna (artículos 8.2.g y 8.3);

- Prohibición de doble enjuiciamiento penal por los mismos hechos o non bis in idem (artículo 8.4);

- Publicidad del proceso o proceso público (artículo 8.5).

En cuanto al artículo 25 de la $\mathrm{CADH}$ en su inciso 1, establece:

"que toda persona tiene derecho a contar con un recurso sencillo y rápido a cualquier otro recurso efectivo ante los jueces o tribunales competentes, que la ampare contra actos que violen sus derechos fundamentales, reconocidos por la Constitución, la ley o la presente Convención".

\footnotetext{
${ }^{73}$ Ibídem.

${ }^{74}$ Huerta Guerrero, Luis Alberto (2007), p. 711.
} 
La Corte Interamericana ha señalado que, entre estos mecanismos de protección judicial, se hayan los procesos de amparo y hábeas corpus.

Entre las diferentes situaciones lesivas del derecho a la protección judicial de los derechos fundamentales, la Corte Interamericana ha comprendido para los casos de excepción, el impedimento para presentar una demanda de protección judicial de los derechos fundamentales durante los estados de excepción ${ }^{75}$.

En este punto, la Corte Interamericana destacó que ninguna circunstancia puede ni debe obstaculizar, para que una persona, durante los casos de excepción pueda acudir ante las autoridades de su país, con el fin de pedir protección de sus derechos fundamentales.

\subsection{El per saltum interamericano cuando en los supuestos de que las garantías judiciales dejan de ser efectivas a raiz de los estados de emergencia}

El sistema interamericano de protección de los derechos humanos reviste carácter "coadyuvante o complementario" a la jurisdicción interna de los Estados, circunstancia que impide acudir directamente a los órganos del Pacto de San José. La Corte y Comisión sólo entran a funcionar en materia contenciosa, una vez que se hayan agotado las instancias internas de los Estados. ${ }^{76}$ Esto es lo que se denomina "Regla del Previo Agotamiento de los Recursos Internos"77. Debe quedar en claro, como punto de partida, que "la competencia internacional es, en general y de principio, 'subsidiaria' respecto a la protección interna de los Derechos Humanos, derecho que los Estados tienen el deber impuesto por el Derecho Internacional, de respetar y garantizar"

Esta regla no es absoluta, sino que reconoce tres excepciones previstas expresamente por la C.A.D.H. y por el Reglamento de la Comisión Interamericana. Verificadas éstas, los peticionarios pueden someter sus pretensiones ante la Comisión Interamericana de Derechos Humanos, sin necesidad de haber interpuesto y agotado todos los recursos previstos por la legislación del Estado. Se abrevia el iter procesal que ordinariamente debe recorrerse, permitiendo un salto de instancia supra nacional.

\footnotetext{
${ }^{75}$ Ibídem.

${ }^{76}$ Cfr. Hitters, Juan Carlos (1995), p. 626.

${ }^{77} \mathrm{La}$ Regla del previo agotamiento de los recursos internos se encuentra expresamente prevista en el preámbulo, arts. 46.1 y 61.2 de la CADH y arts. 23, 28 y 30 del Reglamento de la Comisión IDH.

${ }^{78}$ Gros Espiell, Héctor (1985), p. 18-24, citado por Landoni Sosa, Ángel (2004), p. 464.
} 
Tradicionalmente, y en función de las disposiciones de los tratados internacionales, se ha considerado que las situaciones que eximen el cumplimiento del requisito del previo agotamiento de los recursos internos son:

- La inexistencia en la legislación interna del Estado de que se trata del debido proceso legal para la protección del derecho o derechos que se alega han sido violados;

- Cuando no se haya permitido al presunto lesionado en sus derechos el acceso a los recursos de la jurisdicción interna, o haya sido impedido de agotarlos,

- El retardo injustificado en la decisión de los recursos internos. ${ }^{79}$

Es menester poner de resalto, que la regla del previo agotamiento de los recursos internos no sólo reconoce al Estado el citado derecho de resolver las disputas en su ámbito doméstico antes de que sean llevadas al conocimiento de los tribunales regionales, sino que también le impone la obligación de proporcionar a las personas bajo su jurisdicción recursos judiciales adecuados para proteger la situación jurídica infringida y efectivos para producir el resultado para el que fueron concebidos (art. 25 C.A.D.H.).

Asimismo, se obliga a que dichos recursos sean sustanciados de conformidad con las reglas del debido proceso legal (artículo 8.1). De este modo, la regla del agotamiento de los recursos internos presupone que un Estado no sólo está obligado a ofrecer vías judiciales efectivas, sino también a garantizar que las mismas se sustancien con respeto de las normas del debido proceso. Esto es así, pues la efectividad misma de los recursos depende en gran medida de que en su tramitación se respeten las debidas garantías.

El incumplimiento del Estado de esta obligación releva a los peticionarios de la interposición y agotamiento de los recursos de jurisdicción interna, pudiendo saltar a la Comisión Interamericana de Derechos Humanos.

Este deber del Estado asume una gran importancia para la correcta interpretación y aplicación de la regla general. Al decir de Cançado Trindade ${ }^{80}$, "se nao existiese o dever dos Estados demandados de prover recursos internos eficaces, a regra do esgotamento simplesmente nao teria qualquer lugar no dominio da proteçao dos direitos humanos".

Así como en el siglo XX se produjo la internacionalización de los derechos humanos y su positivización mediante tratados internacionales, la Corte y Comisión Interamericanas proponen que ahora es tiempo de bregar por la efectiva realización de los mismos. "Efectividad" es un término que repite recurrentemente

\footnotetext{
${ }^{79}$ Cfr. Art. 46.2 de la CADH y art. 31 del Reglamento de la Comisión IDH.

${ }^{80}$ Cançado Trindade, Antonio Augusto (1998).
} 
desde el año 1980 hasta el año 2009 en, prácticamente, todos los informes de admisibilidad de la Comisión y en las sentencias de la Corte, y éstas han utilizado como prisma para renovar la forma de aplicar la regla del previo agotamiento. Así, han considerado que el criterio de efectividad es el fundamento que subyace en las excepciones del art. 46.2 y también, lo han utilizado como puerta de apertura a nuevas situaciones que, pese a no estar plasmadas en la letra de dicho artículo, habilitan el no agotamiento de recursos internos que no sean efectivos. Todo ello, se resume en una regla: "cuando los recursos y garantías no son efectivos no es necesario su agotamiento's1.

${ }^{81}$ Corte Interamericana de Derechos Humanos: "Velásquez Rodríguez vs. Honduras" Serie C - No 2: 26 de junio de 1987, Sentencia (excepciones preliminares) párr. 91; "Godinez Cruz vs. Honduras" Serie C - No 2: 26 de junio de 1987, Sentencia (excepciones preliminares) párr. 84; Caso "Caballero Delgado y Santana vs. Colombia” Serie C - No 7, 21 de enero de 1994, Sentencia (excepciones preliminares) párrs. 63-64; Caso "Cantoral Benavides vs. Perú" Serie C - No 40: 27 de agosto de 1998, Sentencia (excepciones); Caso "Cesti Hurtado vs. Perú"Serie C - No 49: 26 de enero de 1999, Sentencia (excepciones preliminares) párr. 33; Caso "Durandy Ugarte vs. Perú" Serie C- No 50: 28 de mayo de 1999, Sentencia (excepciones preliminares) párr. 33; Caso "Comunidad Mayagna vs. Nicaragua" Serie C - No 66: 1 de febrero de 2000, Sentencia (excepciones preliminares) párr. 53; Caso "Herrera Ulloa vs. Costa Rica" Serie C - No 107: 2 de julio de 2004, Sentencia (excepciones preliminares, fondo, reparaciones y costas) párr. 84; Caso "Tibi vs. Ecuador"Serie C - No 114: 7 de septiembre de 2004, Sentencia (excepciones preliminares) párr. 50; Caso "Las Niñas Yean y Bosico Vs. República Dominicana" Serie C - No 130: 8 de septiembre de 2005, Sentencia (excepciones preliminares) párr. 60; Caso "Ximenes Lopes Vs. Brasil" Serie C - No 139: 30 de noviembre de 2005, Sentencia (excepciones preliminares) párr. 4; Caso "Acevedo Jaramillo y otros Vs. Perú" Serie C - No 144: 7 de febrero de 2006, Sentencia (excepciones preliminares) párr. 123.

Así lo sostuvo la Corte en el Caso "Velásquez Rodríguez vs. Honduras" Serie C - No 2: 26 de junio de 1987, Sentencia (excepciones preliminares) párr. 91; "Godínez Cruz vs. Honduras" Serie C - No 2: 26 de junio de 1987, Sentencia (excepciones preliminares) párr. 84; Caso "Caballero Delgado y Santana vs. Colombia" Serie C - No 7, 21 de enero de 1994, Sentencia (excepciones preliminares) párrs. 63-64; Caso "Cantoral Benavides vs. Perú" Serie C- No 40: 27 de agosto de 1998, Sentencia (excepciones); Caso "Cesti Hurtado vs. Perú"Serie C- No 49: 26 de enero de 1999, Sentencia (excepciones preliminares) párr. 33; Caso "Durand y Ugarte vs. Perú" Serie C- No 50: 28 de mayo de 1999, Sentencia (excepciones preliminares) párr. 33; Caso "Comunidad Mayagna vs. Nicaragua"Serie C - No 66: 1 de febrero de 2000, Sentencia (excepciones preliminares) párr. 53; Caso "Herrera Ulloa vs. Costa Rica"Serie C - No 107: 2 de julio de 2004, Sentencia (excepciones preliminares, fondo, reparaciones y costas) párr. 84; Caso "Tibi vs. Ecuador" Serie C - No 114: 7 de septiembre de 2004, Sentencia (excepciones preliminares) párr. 50; Caso "Las Niñas Yean y Bosico Vs. República Dominicana" Serie C - No 130: 8 de septiembre de 2005, Sentencia (excepciones preliminares) párr. 60; Caso "Ximenes Lopes Vs. Brasil" Serie C - No 139: 30 de noviembre de 2005, Sentencia (excepciones preliminares) párr. 4; Caso "Acevedo Jaramillo y otros Vs. Perú" Serie C - No 144: 7 de febrero de 2006, Sentencia (excepciones preliminares) párr. 123; "Hermanas Serrano Cruz Vs. El Salvador" Serie C - No 118: 23 de noviembre de 2004, Sentencia (excepciones preliminares) párr. 140.

Comisión Interamericana de Derechos Humanos: Informe 63/04 sobre petición 60-2003 -HONDURAS-; Informe No $1 / 95$ sobre petición No 11.006 -PERÚ-; Informe 31/93 sobre caso No 10.573 -ESTADOS UNIDOS-; Informe 10/95 sobre caso No 10.580 -ECUADOR-; Informe 5/96 sobre caso No 10.970 -PERÚ-; Informe 5/97 sobre caso No 11.227 -COLOMBIA-; Informe No 33/97 sobre caso No 11.405 -BRASIL-; Informe No 28/98 sobre caso No 11.625 -GUATEMALA-; Informe 84/98 sobre caso No 11.710 -COLOMBIA-; Informe No $42 / 99$ sobre caso No 11.045 -PERÚ-; Informe No 68/99 sobre 


\section{LA SUSPENSIÓN DE LAS GARANTÍAS EN ESTADOS DE EMERGENCIA EN EL MERCOSUR}

Para poder ser Estado parte del MERCOSUR, se exige tener un régimen democrático de gobierno. Cabe preguntarnos, ¿a qué democracia se refiere este mandato? ¿Qué lugar ocupan las garantías en esta prescripción?

Tradicionalmente se ha definido Democracia como una forma de gobierno caracterizada porque el poder reside en el pueblo y es éste el que gobierna a través de sus representantes. Esto es la democracia, pero no la democracia en sí, pues existen otras dimensiones que son constitutivas de la misma y cuya omisión acarrearía graves consecuencias. ${ }^{82}$ En la hora actual, el proceso de constitucionalización de los derechos humanos nos obliga a realizar una relectura del término, a la luz de los derechos humanos y las garantías judiciales en los Estados democráticos.

Con este temperamento, la Corte Interamericana de Derechos Humanos, ha dicho que "[e]n una sociedad democrática los derechos y libertades inherentes a la persona, sus garantías y el Estado de Derecho constituyen una tríada, cada uno de cuyos componentes se define, completa y adquiere sentido en función de los otros ${ }^{\prime 3}$ En este orden de ideas, ha apuntado también que "el sistema democrático (...) dispone limites infranqueables en cuanto a la vigencia constante de ciertos derechos esenciales de la persona" ${ }^{84}$ Es decir, que no se puede concebir democracia sin

caso No 11.079 -BRASIL-; Informe No 61/00 sobre caso No 12.058 -BRASIL-; Informe No 78/00 sobre petición 11.753 -ESTADOS UNIDOS-; Informe No 51/00 sobre caso No 11.193 -ESTADOS UNIDOS-; Informe No 33/01 sobre caso No 11.552; -BRASIL-; Informe No 118/01 sobre caso No 12.230 -NICARAGUA-; Informe No 05/02 sobre petición 12.080 -ARGENTINA-; Informe 15/02 sobre petición 11.802 -HONDURAS-; Informe 13/02 sobre petición 11.171 -GUATEMALA-; Informe 14/02 sobre petición No 12.352 -GUATEMALA-; Informe No 1/03 sobre petición 12.221 -ARGENTINA-; Informe No 3/03 sobre petición 12.257 -ARGENTINA-; Informe No 60/03 sobre petición No 12.108 -CHILE-; Informe No 9/05 sobre petición No 1-03 -ECUADOR-; Informe No 14-05 sobre petición 3101-02 -HONDURAS-; Informe No 16/06 sobre petición No 609-01 -ARGENTINA-; Informe No 26/06 sobre petición No 434-03 -ESTADOS UNIDOS-; Informe No 17/06 sobre petición No 531-01 -ARGENTINA-; Informe No 18/06 sobre petición No 12.353 -BRASIL-; Informe 19/92 sobre caso No 10.865-ESTADOS UNIDOS-; Informe No 24/99 sobre caso 11.812 -MÉXICO-; Informe No sobre caso No 11.797 -VENEZUELA-.

${ }^{82}$ Cfr. Del Barco, Ricardo (2007), p. 117.

${ }^{83}$ Corte Interamericana de Derechos Humanos, Opinión Consultiva OC-8/87del 30 de enero de 1987, "El hábeas corpus bajo suspensión de garantías" - Arts. 27.2, 25.1 y 7.6 CONVENCIÓN AMERICANA SOBRE DERECHOS HUMANOS - párr. 26, [fecha de consulta: 01/07/09]. Disponible en: http://www. corteidh.or.cr/docs/opiniones /seriea_09_esp.doc

${ }^{84}$ Corte Interamericana de Derechos Humanos, Opinión Consultiva OC OC-8/87 del 30 de enero de 1987, "El hábeas corpus bajo suspensión de garantías" - Arts. 27.2, 25.1 y 7.6 CONVENCIÓN AMERICANA SOBRE DERECHOS HUMANOS - párr. 20 in fine, [fecha de consulta: 01/07/09]. Disponible en: http:// www.corteidh.or.cr/docs/ opiniones/seriea_09_esp.doc 
garantías ni derechos humanos. Son conceptos interdependientes que se definen recíprocamente.

En el mismo sentido, la Corte Suprema de la Nación argentina, ha manifestado que la vigencia de las garantías individuales constituye un principio fundamental de las democracias modernas ${ }^{85}$.

En mérito de los argumentos vertidos, se colige que en el MERCOSUR las garantías judiciales asumen una importancia superlativa, por cuanto constituyen los cimientos sobre los cuales descansa el régimen democrático de los Estados que forman parte del proceso de integración. Va de suyo que, si bajo el argumento de los estados de emergencia, se suspenden o privan de efectividad a las garantías judiciales esenciales, se estaría afectando una norma basal del MERCOSUR.

\section{CONClusiones}

1. La doctrina de la emergencia ha degradado y degrada el sistema republicano y la concepción del Estado constitucional de derecho. Las consecuencias para el sistema son graves: la afectación de la seguridad jurídica, restricción y limitación irrazonable de garantías y derechos fundamentales.

2. Las emergencias tienen diversos orígenes, ya sean de carácter político, social, sanitario, económico, judicial, físico, pero también tienen limitaciones sustantivas y adjetivas previstas en el bloque de constitucionalidad (límites de tiempo, límites de materia, límites en la razonabilidad de las medidas). De ello se sigue la posibilidad de someterlas a un test de constitucionalidad y convencionalidad.

3. La "emergencia [funciona en la praxis] como generadora de más emergencia" ${ }^{86}$ Su permanencia injustificada en el tiempo pone en emergencia a la Constitución misma y opera como un factor determinante de "desconstitucionalización" y "desmontaje constitucional".

4. Los textos constitucionales y tratados de derechos humanos habilitan que en situaciones de emergencia el Poder Público aumente circunstancial y transitoriamente la órbita de sus competencias, con desplazamientos de facultades a favor de uno de su órganos (Poder Ejecutivo), para enfrentar y neutralizar la situación de excepción. La experiencia demuestra abusos que repercuten en restricciones injustificadas de derechos personales, libertades y garantías.

5. Las garantías judiciales constituyen vías para reclamar la tutela de derechos fundamentales. La CIDH sostiene la imposibilidad de suspender las garantías

${ }^{85}$ Corte Suprema de Justicia de la Nación, Caso “Gauna Juan O.” (07/05/1997), La Ley, 1997-C, 517.

${ }^{86}$ CaYuso, Susana (2005): "La emergencia económica y la Constitución. Crónica de un pasado y presente contradictorios y de un futuro incierto. En busca de los controles perdidos" en La Ley (2005-C, 1319). 
judiciales esenciales en tiempos de emergencia, entre las cuales se destacan el amparo y hábeas corpus. Todo ello, con fundamento legal en el art. 27 de la $\mathrm{CADH}$, jurisprudencia y opiniones consultivas.

6. La falta de efectividad de un recurso judicial, contra la vulneración de los derechos protegidos por la $\mathrm{CADH}$, hace transgredir al Estado, por cuanto este medio no fue idóneo para evitar la violación de los derechos humanos.

7. La CIDH estableció que cuando los recursos judiciales y garantías no son efectivos para proteger la situación jurídica infringida a los derechos de las personas, no es necesario el agotamiento de los recursos internos. Se sustituye la regla del previo agotamiento de estos recursos por el per saltum o salto de instancia supranacional a los órganos del Pacto de San José de Costa Rica.

8. En el MERCOSUR, es condición insoslayable para ser Estado Parte, que sea democrático. La Corte Interamericana estableció que en una sociedad democrática, los derechos y libertades inherentes a la persona, sus garantías y el Estado de Derecho constituyen una tríada, cada uno de cuyos componentes se define, completa y adquiere sentido en función de los otros. Por lo que la afectación de uno de ellos trae consigo la afectación de una norma basal del MERCOSUR.

9. Aun en los estados de emergencia, debe tenerse presente en la interpretación y aplicación de las normas en pos de la tutela efectiva de los derechos fundamentales de la persona humana.

\section{BiBLIOGRAFÍA}

Ackerman, Bruce (2004): “The Emergency Constitution” en Yale Law Journal (Vol 113:1029).

Alvarado Velloso, Adolfo (1998): Introducción al Estudio del Derecho Procesal. Primera Parte (Santa Fe, Rubinzal Culzoni).

BADENI, Gregorio (2008): "Emergencia económica y Estado de Derecho" en La Ley (2007-A, 1039 -Derecho Constitucional - Doctrinas Esenciales 193).

BALKIn, Jack y Levinson, Sanford (2010): ¿What are de facts of Marbury vs. Madison? [fecha de consulta: 23/05/10]. Disponible en acervo virtual de la Universidad de Yale, sección artículos del Profesor de Derecho Constitucional Jack Balkin: http://www.yale.edu/lawweb/jbalkin/articles/whatarethefactsofmarbury1.pdf

Bermúdez Tapia, Manuel Alexis (2007): La Constitución a través de las Sentencias del Tribunal Constitucional (Lima, Ediciones Legales).

BidarT CAMpos, Germán J. (2000): Manual de la Constitución Reformada (Buenos Aires, Ediar). 
Burelli, Alirio Abreu (2007): "Independencia Judicial - Independencia de la Corte Interamericana de Derechos Humanos" en Anuario de Derecho Constitucional Latinoamericano de la Fundación Konrad Adenauer ( 3 o Año - Tomo II).

Cabanellas, Guillermo (1953): Diccionario de Derecho Usual (Buenos Aires, Arayú).

Cançado Trindade, Antonio Augusto (1998): "A regra do esgotamiento dos recursos internos revistada” en Liber Amicorum-Héctor Fix Zamudio (San José de Costa Rica, Secretaría de la Corte Interamericana de Derechos Humanos) volumen I [fecha de consulta 01/03/10]. Disponible en: http://www.coteidh. or.cr/publica/FixVol1.pdf

CArrió, Genaro R. (1973): Notas sobre Derecho y Lenguaje (Buenos Aires: Abeledo Perrot, Buenos Aires).

CaYuso, Susana (2003): "Emergencia, razonabilidad y cuestión constitucional" en La Ley (2004-A, 1309-Sup. E. Emerg. Económica y Rec. Extraordinario No 37).

CAYUSO, Susana (2005): "La emergencia económica y la Constitución. Crónica de un pasado y presente contradictorios y de un futuro incierto. En busca de los controles perdidos” en La Ley (2005-C, 1319).

Cea Egaña, José Luis (1997): "Los tratados de derechos humanos y la Constitución Política de la República” en Ius et Praxis-Universidad de Talca-Facultad de Ciencias Jurídicas y Sociales (Año 2, No 2).

Dalla Vía, Alberto Ricardo (2009): "La doctrina constitucional de la emergencia y el derecho de propiedad" [fecha de consulta: 01/07/09]. Disponible en página de la Asociación Argentina de Derecho Constitucional: http://www.aadconst. org/ index.php?option=com_content\&task=view\&id=122\&Itemid=1

Del Barco, Ricardo (2007): "La democracia pluralista" en Derechos Humanos y Democracia. Conmemoración de los 70 años de la visita del filósofo francés a Córdoba" (Córdoba, Alveroni).

Díaz Revorio, F. Javier (2004): Textos Constitucionales Históricos - El Constitucionalismo Europeo y Americano (Lima, Palestra Editores).

Domínguez Zorrego, Manuel (1993): "Estados Excepcionales y Garantías de los Derechos Fundamentales en Latinoamérica” en Revista de Estudios Políticos del Centro de Estudios Políticos y Constitucionales de España (Nueva Época, No 81).

Feming, Abel y Lodeiro, Fernando -presidente y secretario de la Federación Argentina de la Magistratura-: "Federación Argentina de la Magistratura. Justicia y Seguridad. Qué proponemos hacer" [fecha de consulta: 01/07/09]. Disponible en: http://www.fam.org.ar/notas.asp?id=306 
Fernández González, Miguel Ángel (octubre de 2002/marzo de 2003): “Los estados de excepción en la Constitución chilena" en Debates de ActualidadRevista de la Asociación Argentina de Derecho Constitucional (año XVIII - No 189).

Fernández Segado, Francisco (2009): La Justicia Constitucional: Una Visión desde el Derecho Comparado (Madrid, Dikinson).

Ferreyra, Raúl Gustavo (2003): “'Tiempo Constitucional? La Constitución Vulnerable” [fecha de consulta: 01/04/09]. Disponible en: http://www.justierradelfuego.gov.ar/Jornadas/Ferreyra.htm.

González, Joaquín V. (1964): Manual de la Constitución Argentina (Córdoba, Universidad Nacional de Córdoba).

Gros Espiell, Héctor (1991): Derechos Humanos, Instituto Peruano de Derechos Humanos (Lima, Cultural Cuzco S.A. Editores).

Habërle, Peter (2001): El Estado Constitucional (Perú, Universidad Nacional Autónoma de México y Pontificia Universidad Católica del Perú).

Haro, Ricardo (2008): Control de Constitucionalidad, 2a Edición (Buenos Aires, Zavalía).

HeRnÁNDEZ, Antonio María (2007): "El regreso a la jurisprudencia convalidatoria de la emergencia económica", en Revista Debates de Actualidad, Asociación Argentina de Derecho Constitucional (Año XXII- No 198).

HitTers, Juan Carlos (1995): "El Derecho Procesal Trasnacional" en Homenaje Escuela Procesal de Córdoba - Dedicado a la memoria de Jorge A. Clariá Olmedo y Alfredo Vélez Mariconde - Instituto de Derecho Procesal y Centros de Estudios de Derecho Procesal Provinciales y Extranjeros (Córdoba, Marcos Lerner).

Huerta Guerrero, Luis Alberto (2007): "Reflexiones sobre las sentencias de fondo de la Corte Interamericana de Derechos Humanos en el caso Hilari, Constantine, Benjamín y otros, relativo a la aplicación de la pena de muerte en Trinidad y Tobago" en Anuario de Derecho Constitucional Latinoamericano de la Fundación Konrad Adenauer (13o Año - Tomo II).

Landoni SosA, Ángel (2004): "El Proceso Trasnacional” en XIV Jornadas Iberoamericanas de Derecho Procesal (La Plata, Impresiones Avellaneda S.A.).

MENÉNDEZ, Florentín (2004): Instrumentos Internacionales sobre Derechos Humanos (México, Fundación Konrad Adenauer).

Mezzetti, Luca (2000): La Democrazie Incerte. Transicioni constituzionali e consolidamento della democracia in Europa Orientale, Africa, América Latina y Asia, Centro Italiano per lo Sviluppo della Ricerca (CISR) Collana diretta dal. Prof. Giuseppe de Vergottini (No 19, Torino, G. Giappichelli Editore). 
Midón, Mario (2009): "Una respuesta que nos debemos: ¿Por qué vivimos en el reino de la emergentocracia?" [fecha de consulta: 01/07/09]. Disponible en Acervo Virtual de la Academia Nacional de Derecho y Ciencias Sociales de Córdoba: www.acader.unc.edu.ar.

Miller, Jonathan M., Gelli, María Angélica y CaYuso, Susana (1992): Constitución y Poder Político - Jurisprudencia de la Corte Suprema y técnicas para su interpretación (Buenos Aires, Astrea).

MoncaYo, Guillermo R. (1998): "Reforma constitucional, Derechos Humanos y Jurisprudencia de la Corte Suprema” en La aplicación de los tratados sobre derechos humanos por los tribunales locales (Buenos Aires, Del Puerto).

Nino, Carlos Santiago (1992): Fundamentos del Derecho Constitucional (Buenos Aires, Astrea).

Nino, Carlos Santiago (2000): "Introducción al análisis del derecho", Colección Mayor Filosofía y Derecho, 2a Edición ampliada y revisada, 10ª reimpresión (Astrea, Buenos Aires).

Nogueira Alcalá, Humberto (1997): Dogmática constitucional (Chile, Ed. Universidad de Talca).

Nogueira Alcalá, Humberto (2009): "Informe en Derecho sobre moción para restablecer la pena de muerte para determinados delitos" [fecha de consulta: 01/07/10]. Disponible en Ius Et Praxis (v. 15 n. 2) versión on line http://www. scielo.cl/scielo.php?pid=S0718-00122003000200008\&script=sci_arttext.

Real Academia Española (2010): Diccionario de la Lengua Española, Vigésima Segunda Edición [fecha de consulta: 25/04/10]. Disponible en http://buscon. rae.es.

Risso Ferrand, Martín (2007): Algunas garantias básicas de los derechos humanos (Montevideo, Fundación de Cultura Universitaria).

RosatTI, Horacio Daniel (2009): "Un círculo vicioso: impacto de las emergencias continuadas en el diseño institucional de Argentina. Emergencia y división de poderes" [fecha de consulta: 01/07/09]. Disponible en Biblioteca Virtual de la Universidad Autónoma de México: www.juridicas.unam.mx/publica/rev/ $\mathrm{revlad} / \mathrm{cont} / 1 / \mathrm{art} / \mathrm{art} 15 . \mathrm{htm}$.

SALVIOLI, Fabián Omar (1997): "Cuestiones sobre la Jurisprudencia interamericana" en Suplemento Humana IURA de Derechos Humanos del Servicio de Publicaciones de la Universidad de Navarra, España (No 7).

SAGÜÉs, Néstor Pedro (2009): "El Control de Convencionalidad. En particular sobre las Constituciones Nacionales” en La Ley (Año LXXIII, No 35).

SAGÜÉs, Néstor Pedro (2004): "Conexiones entre la declaración del estado de emergencia económica en el derecho constitucional argentino y en el pacto de 
San José de Costa Rica. Su control judicial”, en La Ley (2004-A, 1318 - Sup.

E. Emerg. Económica y Rec. Extraordinario No 46).

SAGÜÉs, Néstor Pedro (2007): "El Concepto de Desconstitucionalización", trabajo presentado en el XIII Encuentro Argentino de Profesores de Derecho Constitucional organizado por la Asociación Argentina de Derecho Constitucional en septiembre de 2007 [fecha de consulta: 25/05/10]. Disponible en http:// encuentroparana.aadconst.org/archivos/ponencia-01.pdf.

SenZ J., Luis Felipe (2006): "La regulación de los Estados de excepción en Guatemala y la necesidad de reforma de la Ley de Orden Público y que los contiene, para su congruencia con la normativa de la Constitución Política de la República de Guatemala” en Anuario de Derecho Constitucional Latinoamericano (12 año, Tomo 1, Montevideo, Konrad Adenauer Stiftung).

Tribe, Lawrence y Gudridge, Patrick O. (2004): “The Anti-Emergency Constitution” en Yale Journal Law (Vol. 113:1801).

TYler, Amanda (2009): "Suspension as an Emergency Power" en Yale Law Journal (Vol. 118:600).

Vermeule, Adrian (2007): "Posner on security and Liberty: Alliance to end repression v. City on Chicago, en Harvard Law Review (EE.UU., 1251).

Zapata Larraín, Patricio (2008): Justicia Constitucional. Teoría y Práctica en el Derecho Chileno y Comparado (Chile, Editorial Jurídica de Chile).

\section{NORMAS}

Declaración Universal de los Derechos Humanos

Declaración de los Derechos del Hombre y del Ciudadano

Convención Americana de los Derechos Humanos

Pacto Internacional de Derechos Civiles y Políticos

Pacto Internacional de Derechos Económicos, Sociales y Culturales

Constitución de la República Argentina

Constitución de la República Federal de Alemania

Constitución de la República Federativa do Brasil

Constitución de la República de Chile

Constitución de la República de Costa Rica

Constitución de España

Constitución de los Estados Unidos de América

Constitución de la República de Francia

Constitución de la República de Honduras 
Constitución de la República de Hungría

Constitución de los Estados Unidos Mexicanos

Constitución de República del Perú

Constitución de República de Polonia

Constitución de Rumania

Constitución de la Federación Rusa

\section{LEgisLaCión ARgENTINA}

- Ley No 16.986, “Acción de Amparo”. B.O. 20/10/1966.

- Ley No 17.454, “Código Procesal Civil y Comercial de la Nación”, B.O. 27/08/1981.

- Ley No 23.098, "Hábeas Corpus”. B.O. 25/10/1984.

- Ley No 25.326, "Hábeas Data”. B.O. 02/11/2000.

- Ley No 25.466, “Intangibilidad de los Depósitos”, B.O. 25/09/2001.

- Ley No 25.557, “Corralito Financiero”, B.O. 10/04/1984.

- Ley Nac. 25.561, "Emergencia Pública y Reforma del Régimen Cambiario", B.O. 04/12/2003.

\section{Diarios de Sesiones}

Comisión Redactora (2000): Diario de Sesiones No 30 en la Constitución de la República del Paraguay (Asunción, Latisidata).

\section{Jurisprudencia de la Corte Suprema de Justicia DE LA NaCión Argentina}

"Ercolano c. Lanteri" (1922): CSJN 28 de abril de 1922 (inconstitucionalidad de la Ley No 11.157) en: Sup. Emergencia Económica y Teoría del Derecho 2003 (agosto), 75 - Colección de Análisis Jurisprudencial Contratos Civiles y Comerciales - Colección de Análisis Jurisprudencial Contratos Civiles y Comerciales - Director: Luis F. P. Leiva Fernández - Editorial La Ley, 2002.

"Horta c. Harguindeguy" (1922): CSJN 21 de agosto de 1922 (inconstitucionalidad de la Ley No 11.157) en: Sup. Emergencia Económica y Teoría del Derecho 2003 (agosto), 84 - Colección de Análisis Jurisprudencial Contratos Civiles y Comerciales - Colección de Análisis Jurisprudencial Contratos Civiles y Comerciales - Director: Luis F. P. Leiva Fernández - Editorial La Ley, 2002.

"Cine Callao" (1960): CSJN 22 de junio de 1960 (inconstitucionalidad Ley No 14,226) en: Sup. Emergencia Económica y Teoría del Derecho 2003 (agosto), 
142 - Colección de Análisis Jurisprudencial Contratos Civiles y Comerciales

- Director: Luis F. P. Leiva Fernández - Editorial La Ley, 2002.

"Peralta Luis. A c. Estado Nacional" (1991): CSJN 27 de diciembre de 1990 (amparo) en: Sup. E. Emerg.Económica y Rec. Extraordinario 2003 (diciembre), 135 - Sup. Emergencia Económica y Teoría del Derecho 2003 (agosto), 154 - La Ley 1991-C, 158, con nota de Alberto Bianchi; LLC 1991, 666 - Colección de Análisis Jurisprudencial Teoría General del Derecho - Director: Eduardo Ángel Russo - Editorial La Ley, 2002.

"Irizar c. Provincia de Misiones"(1996): CSJN 12 de septiembre de 1996 (recurso extraordinario) en: La Ley 1997-C, 29, con nota de Germán J. Bidart Campos; DJ 1997-2, 281 - IMP 1997-A, 666 - La Ley 1997-C, 684.

“Gauna Juan O.” (1997): CSJN 7 de mayo de 1997 (recurso extraordinario) en: La Ley 1997-C, 517, con nota de Carlos E. Colautti ; Colección de Análisis Jurisprudencial Derecho Constitucional - Director: Daniel Alberto Sabsay, Editorial La Ley 2005, 240, con nota de Agustín Zbar; La Ley 1997-E, 714, con nota de María Angélica Gelli ; DJ 1997-2, 510.

"Banco de Galicia y Buenos Aires s/solicita interv. urgente en: Smith, Carlos A. con P.E.N. s/sumarísimo" (2002): CSJN 1 de febrero de 2002 (emergencia económica) en: Sup. E. Emerg. Económica y Rec. Extraordinario 2003 (diciembre), 158 - Sup. Emergencia Económica y Teoría del Derecho 2003 (agosto), 211 - La Ley 2002-A, 770.

"Provincia de San Luis c. Estado Nacional' (2003): CSJN 5 de marzo de 2003 (emergencia económica) en: Sup. E. Emerg. Económica y Rec. Extraordinario 2003 (diciembre), 178 - La Ley 2003-E, 472, con nota de Mario A. Midón; Sup. Emergencia Económica y Teoría del Derecho 2003 (agosto), 218 - La Ley 2003-B, 537.

\section{Jurisprudencia del Tribunal Constitucional de Perú}

Expte. No 2409 - 2002 - AA (2002): Tribunal Constitucional de Perú, 7 de noviembre de 2002 (Recurso Extraordinario), [fecha de consulta: 23/03/10]. Disponible en: http://www.tc.gob.pe/jurisprudencia/2002/02409-2002-AA. html

Expte. No 0017-2003-AI/TC- Lima. (2003): Tribunal Constitucional de Perú 16 de marzo de 2004 (acción de inconstitucionalid), [fecha de consulta: 23/03/2010]. Disponible en: http://www.tc.gob.pe/jurisprudencia/2004/00017-2003-AI. html 


\section{Corte Interamericana de Derechos Humanos}

Competencia Contenciosa

“Velásquez Rodríguez vs. Honduras" Serie C - No 2: 26 de junio de 1987.

"Godinez Cruz vs. Honduras"Serie C - No 2: 26 de junio de 1987.

"Caballero Delgado y Santana vs. Colombia" Serie C - No 7, 21 de enero de 1994.

“Cantoral Benavides vs. Perú" Serie C - No 40: 27 de agosto de 1998.

"Cesti Hurtado vs. Perú" Serie C - No 49: 26 de enero de 1999.

"Durandy Ugarte vs. Perú" Serie C - No 50: 28 de mayo de 1999.

“Comunidad Mayagna vs. Nicaragua” Serie C - No 66: 1 de febrero de 2000.

"Herrera Ulloa vs. Costa Rica" Serie C - No 107: 2 de julio de 2004.

“Tibi vs. Ecuador"Serie C - No 114: 7 de septiembre de 2004.

"Las Niñas Yean y Bosico vs. República Dominicana" Serie C - No 130: 8 de septiembre de 2005.

“Ximenes Lopes Vs. Brasil"Serie C - No 139: 30 de noviembre de 2005.

“Acevedo Jaramillo y otros vs. Perú" Serie C - No 144: 7 de febrero de 2006.

"Hermanas Serrano Cruz vs. El Salvador" Serie C - No 118: 23 de noviembre de 2004.

\section{Competencia Consultiva}

El Hábeas Corpus Bajo Suspensión de Garantías (arts. 27.2, 25.1 y 7.6 Convención Americana sobre Derechos Humanos). Opinión Consultiva OC-8/87 del 30 de enero de 1987. Serie A N No 8.

Corte IDH. Garantías Judiciales en Estados de Emergencia (arts. 27.2, 25 y 8 Convención Americana sobre Derechos Humanos). Opinión Consultiva OC9/87 del 6 de octubre de 1987. Serie A N No 9.

\section{Comisión Interamericana de Derechos Humanos}

Informe No 63/04 sobre petición 60-2003-HONDURAS-;

Informe No 1/95 sobre petición No 11.006 -PERÚ-;

Informe No 31/93 sobre caso No 10.573 -ESTADOS UNIDOS-;

Informe No 10/95 sobre caso No 10.580 -ECUADOR-;

Informe No 5/96 sobre caso No 10.970 -PERÚ-;

Informe No 5/97 sobre caso No 11.227 -COLOMBIA-;

Informe No 33/97 sobre caso No 11.405 -BRASIL-; 
Informe No 28/98 sobre caso No 11.625 -GUATEMALA-;

Informe No 84/98 sobre caso No 11.710 -COLOMBIA-;

Informe No 42/99 sobre caso No 11.045 -PERÚ-;

Informe No 68/99 sobre caso No 11.079 -BRASIL-;

Informe No 61/00 sobre caso No 12.058 -BRASIL-;

Informe No 78/00 sobre petición 11.753 -ESTADOS UNIDOS-;

Informe No 51/00 sobre caso No 11.193 -ESTADOS UNIDOS-;

Informe No 33/01 sobre caso No 11.552; -BRASIL-;

Informe No 118/01 sobre caso No 12.230 -NICARAGUA-;

Informe No 05/02 sobre petición 12.080 -ARGENTINA-;

Informe No 15/02 sobre petición 11.802 -HONDURAS-;

Informe No 13/02 sobre petición 11.171 -GUATEMALA-;

Informe No 14/02 sobre petición No 12.352 -GUATEMALA-;

Informe No 1/03 sobre petición 12.221 -ARGENTINA-;

Informe No 3/03 sobre petición 12.257 -ARGENTINA-;

Informe No 60/03 sobre petición No 12.108 -CHILE-;

Informe No 9/05 sobre petición No 1-03 -ECUADOR-;

Informe No 14/05 sobre petición 3101-02 -HONDURAS-;

Informe No 16/06 sobre petición No 609-01 -ARGENTINA-;

Informe No 26/06 sobre petición No 434-03 -ESTADOS UNIDOS-;

Informe No 17/06 sobre petición No 531-01 -ARGENTINA-;

Informe No 18/06 sobre petición No 12.353 -BRASIL-;

Informe No 19/92 sobre caso No 10.865 -ESTADOS UNIDOS-;

Informe No 24/99 sobre caso 11.812 -MÉXICO-;

Informe sobre caso No 11.797 -VENEZUELA-. 